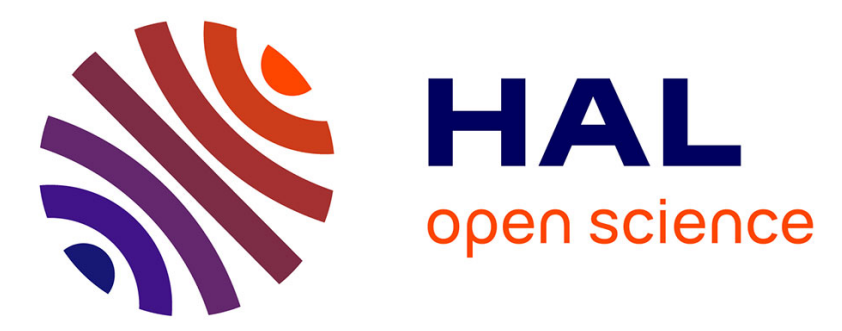

\title{
Active control : an investigation method for combustion instabilities
}

Thierry Poinsot, B. Yip, D. Veynante, Arnaud Trouvé, J. Samaniego, S. Candel

\section{> To cite this version:}

Thierry Poinsot, B. Yip, D. Veynante, Arnaud Trouvé, J. Samaniego, et al.. Active control : an investigation method for combustion instabilities. Journal de Physique III, 1992, 2 (7), pp.1331-1357. 10.1051/jp3:1992103 . jpa-00248805

\section{HAL Id: jpa-00248805 https://hal.science/jpa-00248805}

Submitted on 1 Jan 1992

HAL is a multi-disciplinary open access archive for the deposit and dissemination of scientific research documents, whether they are published or not. The documents may come from teaching and research institutions in France or abroad, or from public or private research centers.
L'archive ouverte pluridisciplinaire HAL, est destinée au dépôt et à la diffusion de documents scientifiques de niveau recherche, publiés ou non, émanant des établissements d'enseignement et de recherche français ou étrangers, des laboratoires publics ou privés. 


\title{
Active control : an investigation method for combustion instabilities
}

\author{
T. Poinsot, B. Yip, D. Veynante, A. Trouvé, J. M. Samaniego and S. Candel \\ E.M2.C. Laboratory, C.N.R.S. and E.C.P., Ecole Centrale Paris, 92295 Châtenay-Malabry, \\ France
}

(Received 17 October 1991, revised 30 January 1992, accepted 28 March 1992)

\begin{abstract}
Closed-loop active control methods and their application to combustion instabilities are discussed. In these methods the instability development is impeded with a feedback control loop : the signal provided by a sensor monitoring the flame or pressure oscillations is processed and sent back to actuators mounted on the combustor or on the feeding system. Different active control systems tested on a non-premixed multiple-flame turbulent combustor are described. These systems can suppress all unstable plane modes of oscillation (i.e. low frequency modes). The active instability control (AIC) also constitutes an original and powerful technique for studies of mechanisms leading to instability or resulting from the instability. Two basic applications of this kind are described. In the first case the flame is initially controlled with AIC, the feedback loop is then switched off and the growth of the instability is analysed through high speed Schlieren cinematography and simultaneous sound pressure and reaction rate measurements. Three phases are identified during the growth of the oscillations: (1) a linear phase where acoustic waves induce a flapping motion of the flame sheets without interaction between sheets, (2) a modulation phase, where flame sheets interact randomly and (3) a nonlinear phase where the flame sheets are broken and a limit cycle is reached. In the second case we investigate different types of flame extinctions associated with combustion instability. It is shown that pressure oscillations may lead to partial or total extinctions. Extinctions occur in various forms but usually follow a rapid growth of pressure oscillations. The flame is extinguished during the modulation phase observed in the initiation experiments. In these studies devoted to transient instability phenomena, the control system constitutes a unique investigation tool because it is difficult to obtain the same information by other means. Implications for modelling and prediction of combustion instabilities are discussed.
\end{abstract}

\section{Introduction.}

Combustion instabilities are encountered in many practical systems such as industrial burners, power plants, jet engine afterburners, ramjet and rocket motors. They are characterized by large amplitude oscillations of the flow parameters. Unstable combustion has many undesirable features because it induces violent oscillations of the flow, mechanical vibrations 
in the combustor structure and in other components of the system, it augments heat transfer rates at the combustor walls, and in extreme cases it leads to the total loss of the system.

While numerous studies have been devoted to combustion instabilities (for reviews of theoretical methods for combustion instabilities see for example Williams 1985, Culick 1988), there is no satisfactory general prediction tools available for such problems. Experimental studies have shown that instability mechanisms are extremely varied and require a one-by-one analysis. Attempts to compare and classify instability phenomena are therefore very limited (Barrère and Williams 1968, Williams 1985). The nonlinear features of the problem are a major difficulty in the development and validation of analytical descriptions. These features manifest themselves in most experiments, where the combustion instabilities are usually observed in the fully nonlinear form of a limit cycle (resonant behavior). The existence of these limit cycles follows a classical scenario of Hopf bifurcation where the initial flow instability leads to a periodic, noisy, stable and undesirable limit cycle where nonlinear effects are dominant (Sparrow 1982). Similar mechanisms may also be found in non reacting flows (Singer and Bau 1991) but from a practical point of view, their occurrence in combustion systems is a central question since it often leads to the loss of the system itself.

The initial instability phase (initiation phase) corresponds to the birth of an instability in a stable reacting flow and is the only true «instability » in this process as it drives the flow from one state (without oscillations) to another (with a resonant periodic behavior). Limit cycles are the result of complex nonlinear interactions between processes which may greatly differ from those involved in the initiation phase. Because the resonant phase is easier to study than the initiation phase, almost all experiments on combustion instabilities have focused on limit cycles. However the initiation mechanisms are of considerable importance, and their analysis may provide valuable information for the following reasons:

(1) The oscillation onset is a key mechanism in combustion instability. If the oscillation onset can be understood and suppressed, most combustion instability problems encountered in practical systems will be solved without further study of the limit cycles.

(2) Most theoretical instability models describe the linear or weakly nonlinear range and consequently they are not easily compared with experimental results obtained from limit cycles. In contrast, the initiation phase corresponds in many cases to fluctuations of small amplitude and is then suitably modeled with a linearized analysis. While this argument is seldom presented by investigators, it certainly raises difficult questions regarding the validity of comparisons between predictions obtained with linear models and measurements carried during established limit cycles. This difficulty can be overcome by developing analytical models for nonlinear combustion instabilities (see for example Culick 1988, Poinsot and Candel 1988) or by using numerical simulation. Direct numerical simulations clearly offer a promising approach for the computation of limit cycles without any linear approximation (Kailasanath et al. 1987, Jou and Menon 1987, Menon and Jou 1987, 1989). Nevertheless, an experimental study of the initiation phase and a comparison with linear models is of primary interest. Such experiments also indicate if the system behaves according to the classical supercritical Hopf bifurcation scenario. This is of course true only for linear initiation phases. Nonlinear instability modes which need a large amplitude initial triggering to grow will not be considered in this article.

(3) In many circumstances, oscillations occurring during the initiation phase do not reach a limit cycle but lead to partial or total flame extinction, thus preventing simple studies of the phenomenon and eventually leading to false conclusions as to what mechanisms are responsible for these extinctions. Many authors suggest that combustion instabilities often occur for operating conditions close to extinction and some of them have been able to show 
that low frequency combustion instabilities may induce flame extinctions (Keller et al. 1982, Sivasegaram and Whitelaw 1987).

Thus the initiation phase is a central aspect of combustion instability, but to date, it has not been studied thoroughly for lack of a reliable experimental method. The initiation phase cannot be controlled and triggered simply. It requires, for example a sudden modification of the flow rate of fuel like that used by Sterling and Zukoski (1987) in a study of the onset of oscillations in a dump combustor, or by Vaneveld et al. (1982) in their investigation of the instability initiation in a backward-facing step combustor. Another ingenious device was used in the rocket instability studies conducted by Crocco and his group (1965). The rocket chamber was artificially stabilized by placing baffles in the cavity. These baffles were rapidly consumed by the intense reaction taking place in the chamber and the instability growth could be observed after a short period of time. However, in these examples, the step variations imposed at the combustor inlet or the baffles placed in the chamber can affect the growth rate of the instability in an undetermined way.

Closed-loop active control constitutes a more flexible and general method for controlling and triggering the instability. This method uses a closed feedback loop involving a flow sensor whose signal is returned to a flow exciter. With appropriate signal processing, the combustion oscillations are suppressed. Closed-loop active control belongs to a more general class of methods which will be presented in section 4 . The utility of this technique is that initiation may be studied by starting from a controlled regime and then breaking the control loop. No modification of the flow conditions is required and the initial instant of the initiation phase is precisely known. The method was used by Heckl (1985) in a Rijke tube experiment, and Langhorne et al. (1988) in a premixed reheat combustor to deduce an estimate of the linear amplification rate and compare it with theoretical predictions. The study of Poinsot et al. (1989a) presents instability growth history curves both in a laminar and in a turbulent burner and shows that the results are independent of the control system parameters. These results provide a reliable and simple measurement of the linear amplification rate and initial frequency of the instability.

Similarly the use of active control provides unique opportunities in the study of oscillationrelated flame extinctions. The ability to repeatably control the moment of extinction allows detailed studies of the phenomenon.

The objective of this work is to further explore different modes of active instability control and demonstrate the possibilities of this tool in experiments on combustion instability research. Two important points must be noted here.

(1) We will not try to establish a complete theory to predict oscillatory combustion. Such work has been the subject of ongoing studies over the years by many groups including ours (Crocco et al. 1962, Crocco 1965, Blosxidge et al. 1988, Poinsot et al. 1986, Culick 1971, 1988, Jou and Menon 1987, Kailasanath et al. 1987a, b, etc.). One of the first results exhibited by these studies is the difficulty of understanding and modeling the dynamic response of the flame to excitations (or its linear transfer function when the problem is linear) although some recent progress has been accomplished in the case of plane flames propagating in a tube (Clavin et al. 1990). When this response is described in a correct way, constructing a model which predicts instability frequencies and unstable modes structures is a lengthy but straightforward problem. Our goal is precisely to show how this response may be studied using active control methods and which kind of information may be obtained.

(2) Similarly, we will not elaborate on the design of the control system. In most cases, simple controllers based on a time delay - gain transfer function are sufficient to provide satisfactory results. We are conscious that a classical control strategy is to use the combustor transfer function to design the controller parameters (Gulati and Mani 1989, Gutmark et al. 
1990). However, as indicated above, the combustor transfer function is precisely what is not known. Indeed, such a linear principle probably does not apply to most combustion instabilities because these phenomena feature strongly nonlinear fluid mechanical interactions. In the case of reacting flows, this classical control strategy might prove difficult to implement and self-adaptive techniques which do not require an a priori knowledge of the combustor transfer function may be best suited to the problem as shown by Billoud et al. (1991).

We will therefore concentrate on the new features offered by active control methods and discuss a specific set of results obtained by applying the AIC method to a non-premixed turbulent combustor developed at the E.M2.C. laboratory (Zikikout 1988, Poinsot et al. 1989a, 1989b) and described in section 2. The combustor exhibits strong combustion instabilities which are described in section 3. The principle of active control is reviewed in section 4. Different control systems have been tested and their performance will be discussed. Section 5 presents results on the initiation mechanisms leading to combustion instability, obtained by the use of active control. These results complement those reported in our previous work (Poinsot et al. 1989a, 1989b). Finally different types of extinctions related to instabilities are identified and studied through the use of active control in section 6 .

The results described here relate to a relatively low heat release (about $100 \mathrm{~kW}$ ). The efficiency of active control methods for high-power systems still remains to be demonstrated. However, the mechanisms which are revealed by the use of active control on the present setup are believed to be generic of combustion instabilities even in more powerful devices.

\section{Experimental configuration and signal processing.}

The turbulent combustor is sketched in figure 1 . It is $30 \mathrm{~cm}$ long and has a rectangular $5 \times 10 \mathrm{~cm}^{2}$ cross section. It is designed to generate a two-dimensional mean flow. The lateral walls of the chamber are quartz windows to allow direct optical access to the flame zone. The combustor outlet is open to ambient air. The upstream end of the chamber is connected to a long duct of the same cross section, which is fitted with instrumentation plugs. One or several B \& K 4136 microphones may be installed in this duct to monitor acoustic pressure

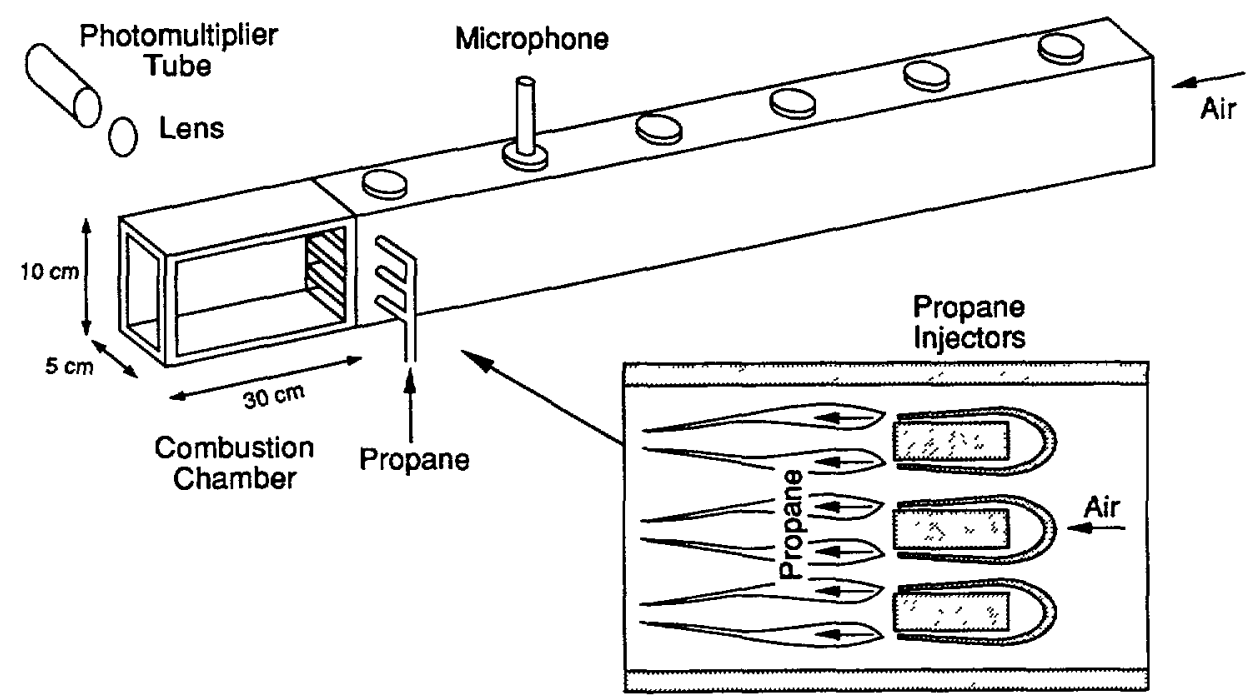

Fig. 1. - Schematic diagram of the turbulent diffusion flame combustor. 
fluctuations in the system. Air is supplied by a blower at the upstream end of the duct, allowing the air flow rate to be adjusted between 35 and $200 \mathrm{~g} / \mathrm{s}$. Propane is injected into the chamber through six narrow rectangular slots. The slots are in recess with respect to three backward facing steps.

A high speed $16 \mathrm{~mm}$ camera (NAC Model E-10 EE) is used with a Schlieren optical set-up to record the flame motions during instability. For the present set of experiments an indication of the global heat release rate in the whole combustor is obtained from measurements of $\mathrm{C}_{2}$ light emission through the combustor windows. Similar techniques are widely used in combustion instability studies (see for example Poinsot et al. 1987). A photomultiplier is used to trace time-variations of the light intensity radiated from the reaction zone. This photomultiplier is equipped with an interferential filter (bandwidth $=50 \mathrm{~nm}$ ) that isolates a characteristic $C_{2}$ emission band $(\lambda=516 \mathrm{~nm})$. Emission from $\mathrm{CH}$ and $\mathrm{OH}$ radicals provide similar results. A more detailed description of the combustor and of some of the instability modes may be found in Zikikout (1988).

A specific requirement of the present work is to perform spectral analysis of rapidly timevarying signals. Procedures for estimating the power spectral density of deterministic or stochastic signals are generally based on the fast Fourier transform (FFT) and are not wellsuited to short data records. To overcome this difficulty, one may use modern nonlinear spectral methods (Veynante and Candel 1988a, 1988b, Kay and Marple 1981). A maximum entropy spectral estimation, developed by Burg and improved by Fougere, is used to reconstruct data from very short sample sequences. The power spectrum is then obtained by maximizing the entropy of the time series under the constraint that the known autocorrelation samples satisfy the Wiener-Khinchin relation (Chen 1982). For each channel (microphone and photomultiplier) 8000 samples are acquired at a frequency of $4000 \mathrm{~Hz}$. Power spectral densities are computed from 60 sample segments, which correspond to a $15 \mathrm{~ms}$ duration. Results are smoothed by averaging over 10 consecutive spectra, yielding a final temporal resolution of $150 \mathrm{~ms}$. This procedure yields the spectral content of the signals up to a frequency of $2000 \mathrm{~Hz}$, by using only 4 cycles of the fundamental instability mode.

\section{Stability and flammability domains.}

The behavior of the combustor described above has a strong dependence on the operating conditions, namely the temperature, air flow rate and the propane flow rate. For a given set of operating conditions, one of the following situations is encountered :

(a) stable operation with fluctuations due only to the turbulent environment. For these regimes the sound pressure level measured in the near field of the combustor remains low (typically 80 or $90 \mathrm{~dB}$ ) and the three flame pairs located behind the backward facing steps burn smoothly;

(b) oscillatory combustion characterized by large pressure fluctuations (120 to $130 \mathrm{~dB}$ in the near field of the device) and a wavy motion of the flame sheets. These regimes correspond to the presence of a combustion instability. Different types of instabilities are observed but two nearly periodic low frequency modes near 190 and $270 \mathrm{~Hz}$ are predominant. As emphasized in the introduction, this state called combustion instability is in fact stable and the corresponding oscillation can be sustained for long periods of time;

(c) partial extinction. Here the flame pair formed by one injector is extinguished. In some cases two flame pairs go out while the third pair subsists ;

(d) complete extinction of the combustor.

Figure $2 \mathrm{a}$ shows the domains of occurrence of these regimes of operation (without control) in a plane where $x$ represents the air flow rate and $y$ the propane flow rate. The combustor 
(a) uncontrolled operation

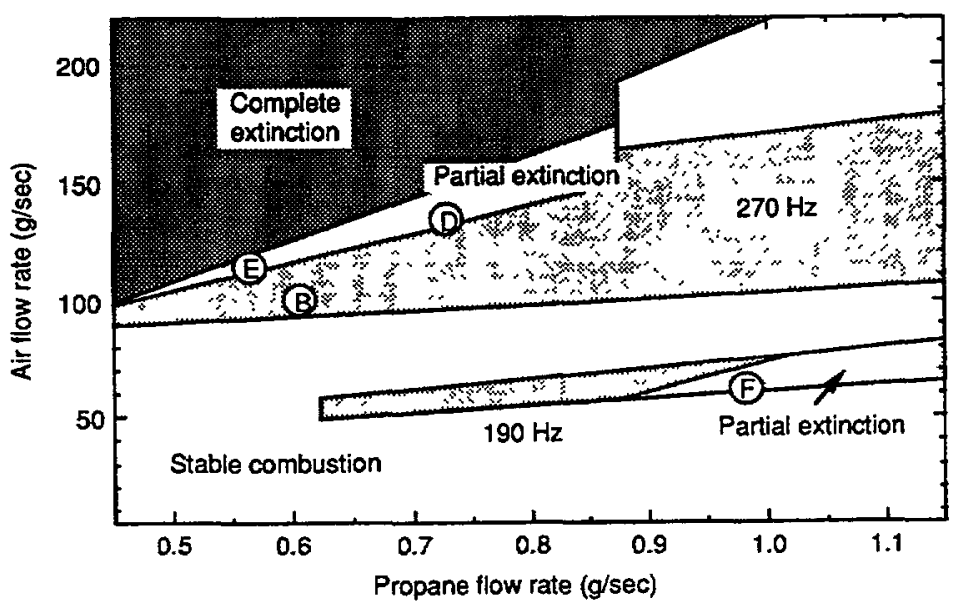

(b) actively-controlled operation

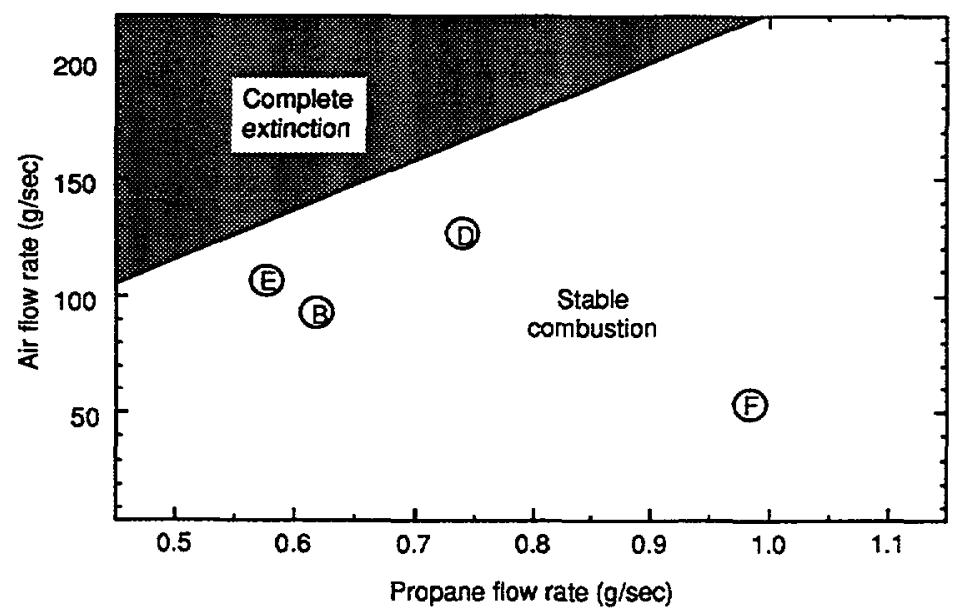

Fig. 2. - Stability and flammability domains in an (air flow rate - propane flow rate) plane without control (a) and with active instability control (b).

exhibits a complex behavior with instabilities occurring near the frequencies $f_{1}=190 \mathrm{~Hz}$, which is predominant under rich conditions, and $f_{2}=270 \mathrm{~Hz}$ which predominates under lean conditions. These two oscillation frequencies exhibit a moderate dependence on the flow rates, increasing by $\sim 30 \mathrm{~Hz}$ for a $20 \%$ increase in air-to-fuel proportion. In some cases, the $270 \mathrm{~Hz}$ mode is accompanied by the extinction of one flame pair (see Sect. 6). The region between the $270 \mathrm{~Hz}$ zone and the complete extinction domain (points D and E in Fig. 2a) is one of partial extinction accompanied in most cases by an oscillation at $270 \mathrm{~Hz}$.

Different observations based on correlations between $C_{2}$ radiation and acoustic pressure measurements suggest that the 190 and $270 \mathrm{~Hz}$ instabilities result from a resonant coupling between the unsteady heat release of the flames and longitudinal acoustic modes of the installation (the 190 and $270 \mathrm{~Hz}$ frequencies correspond to acoustic modes of the entire system from the settling tank located upstream to the exhaust). Figure 3 presents a sequence 

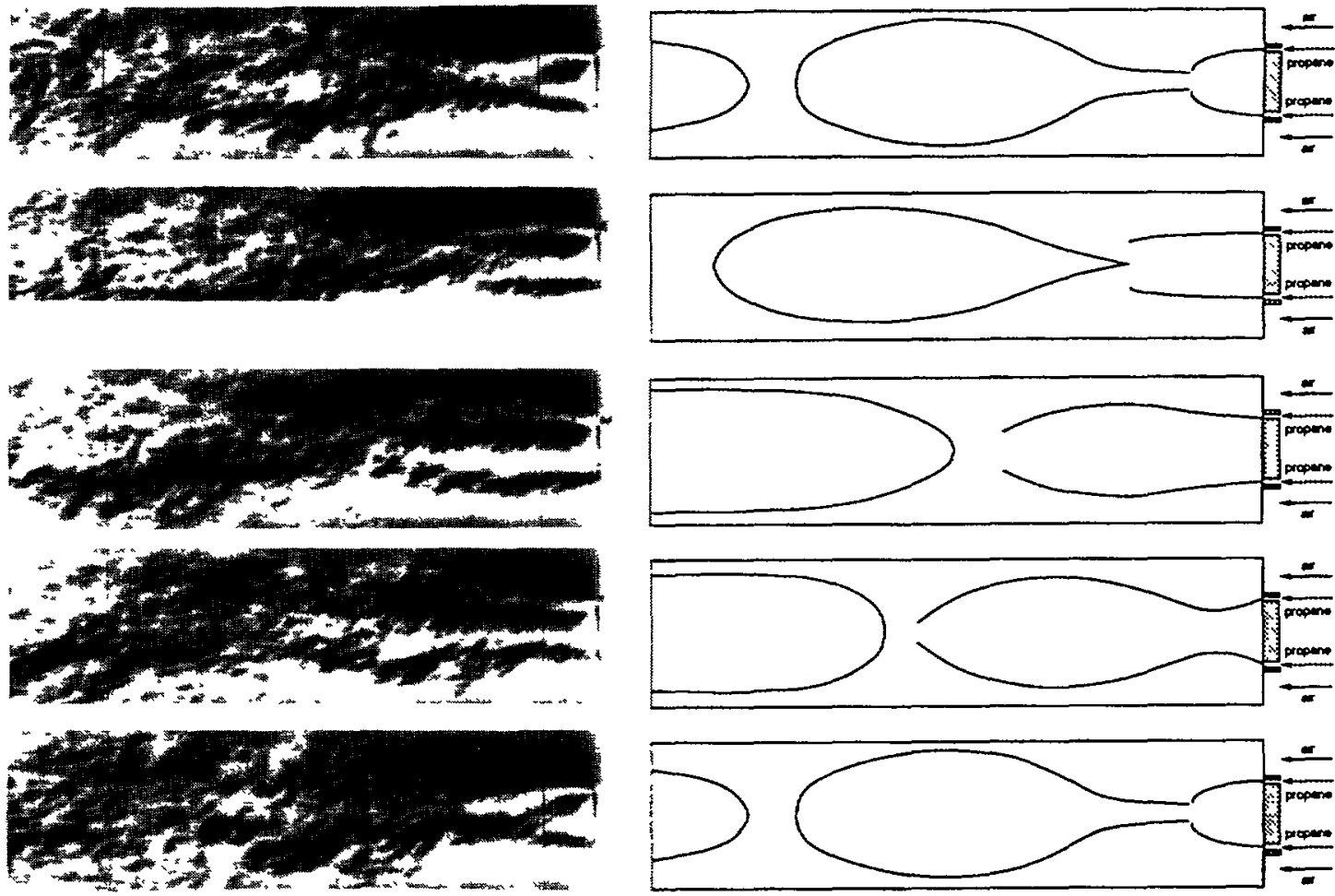

Fig. 3. - Schlieren images and corresponding sketches showing the $270 \mathrm{~Hz}$ combustion oscillation. The flames associated with only one fuel injector are shown - the other two flame pairs behave identically and all three oscillate in phase. The time step between consecutive images is one millisecond.

of Schlieren images of the flame pair behind one propane injection block, taken during the $270 \mathrm{~Hz}$ instability. The other two flame pairs undergo an identical motion with the same phase. The photographs have been extracted from a high speed film recorded at 2000 frames per second and are accompanied by sketches which summarize their salient features. The two plane mixing layers in the wake of the injection block exhibit a breathing motion, which periodically induces a coupling of the two reactive sheets. The intense mixing generated when these sheets collide (in the first and final images of the figure), triggers an increase in the burning rate, as seen by the resultant crinkling of the propane/air interfaces, and the sheets are pushed apart by the volumetric expansion of the burnt gases. The pressure perturbation accompanying the change in heat release feeds energy back to the $270 \mathrm{~Hz}$ longitudinal acoustic mode. The flapping motion is then sustained and a stable oscillation results. It can be seen from the figure that there is no interaction between the flames of neighbouring injectors, nor with the combustor walls.

In contrast, the flapping motion during the $190 \mathrm{~Hz}$ oscillation mode is so violent that there is a coupling between the sheets from adjacent injectors as well as the sheets originating from the same injector. This motion is sketched in figure 4, where again only one of the injectors is shown. Inspection of the high speed Schlieren films corresponding to this oscillation mode indicates that well-defined vortex structures develop and burn in the recirculation zones behind the fuel injector blocks, and play an important role in stabilizing the flames. Like the $270 \mathrm{~Hz}$ mode, this oscillation has been observed to induce flame extinctions. 
(a)

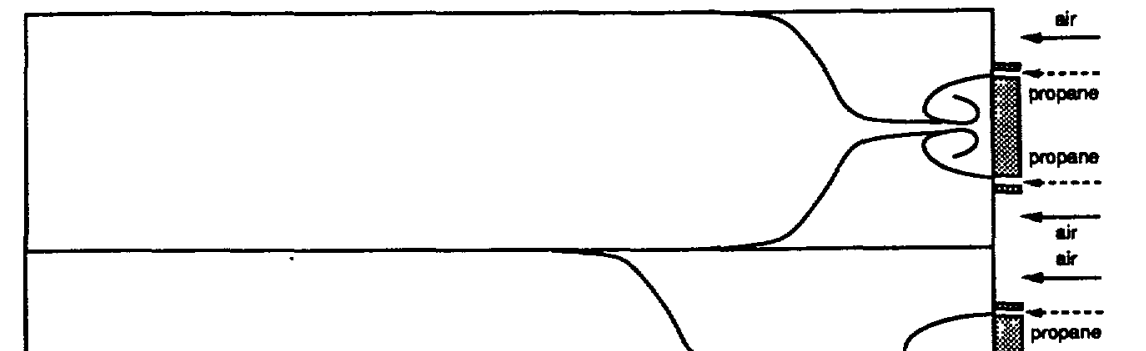

(b)

(c)

(d)

(e)

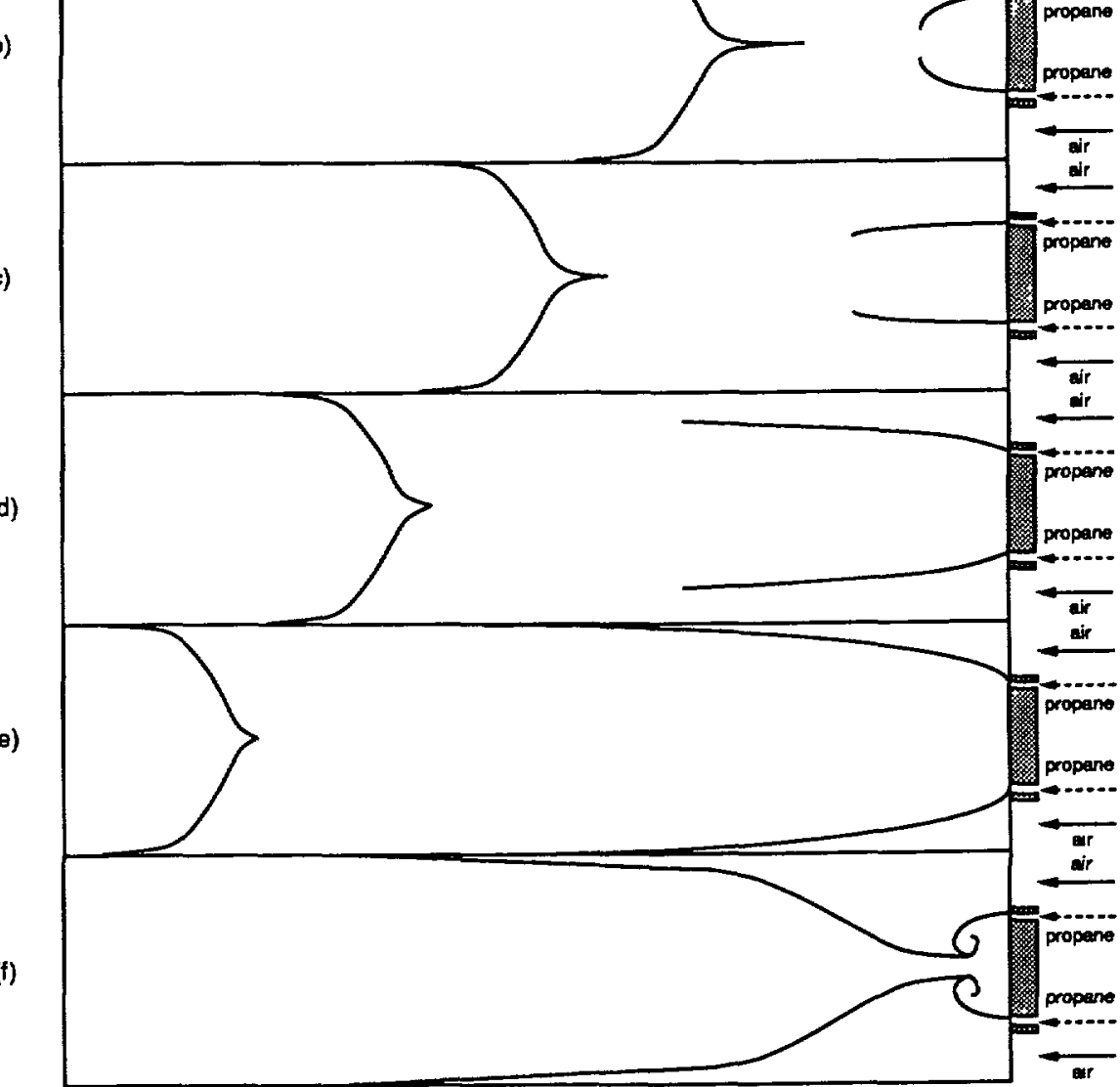

Fig. 4. - Sketches summarizing the salient features seen in Schlieren images of the flames behind one fuel injector, during the $190 \mathrm{~Hz}$ combustion oscillations. The other two flame pairs behave identically and all three oscillate in phase. The time step between consecutive images is one millisecond.

\section{Active control methods.}

While the principles of active control for combustion applications are described in some early studies of Tsien (1952), Marble and Cox (1953), Marble (1955) and Crocco and Cheng (1956), practical demonstration of the concept has only been achieved in the past few years.

Although many "active control » methods have been developed, this rather broad terminology actually refers to very different techniques which have been summarized in Billoud et al. (1991). Only closed-loop non-adaptive control systems have been used in the work presented here. 
Modern closed-loop active control systems are somewhat similar to « anti-sound » (see Ffowcs-Williams 1984, for a review of this subject), the main difference being that they act on the source of instability (the flames) and not only on its effects (the acoustic field). Active control has been used successfully to damp oscillations in Rijke tubes (Heckl 1985), premixed laminars burners (Lang et al. 1987, Sreenivasan et al. 1985), laboratory reheat channels (Dines 1984, Bloxsidge and Langhorne 1986, Bloxsidge et al. 1988, Langhorne et al. 1988), and non-premixed turbulent combustors (Poinsot et al. 1989a, 1989b).

The basic principle of active control is sketched in figure 5. The flame oscillations are detected by a sensor $S$, processed through a transfer function $F$, and the modified output signal is sent back to the flow through an actuator system $E$. The fluid flow and the combustion then interact and provide the coupling which closes the control loop. A suitably chosen transfer function $F$ will provide the negative feedback required to stabilize combustion oscillations. This transfer function may be implemented with analog or numerical filters.

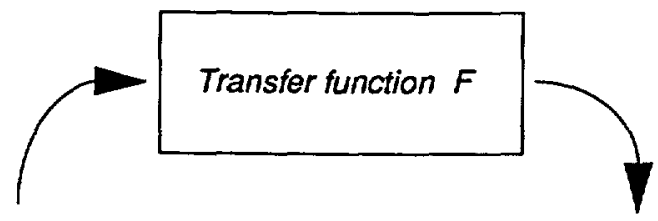

Input sensor $S$

Output excitation device $E$

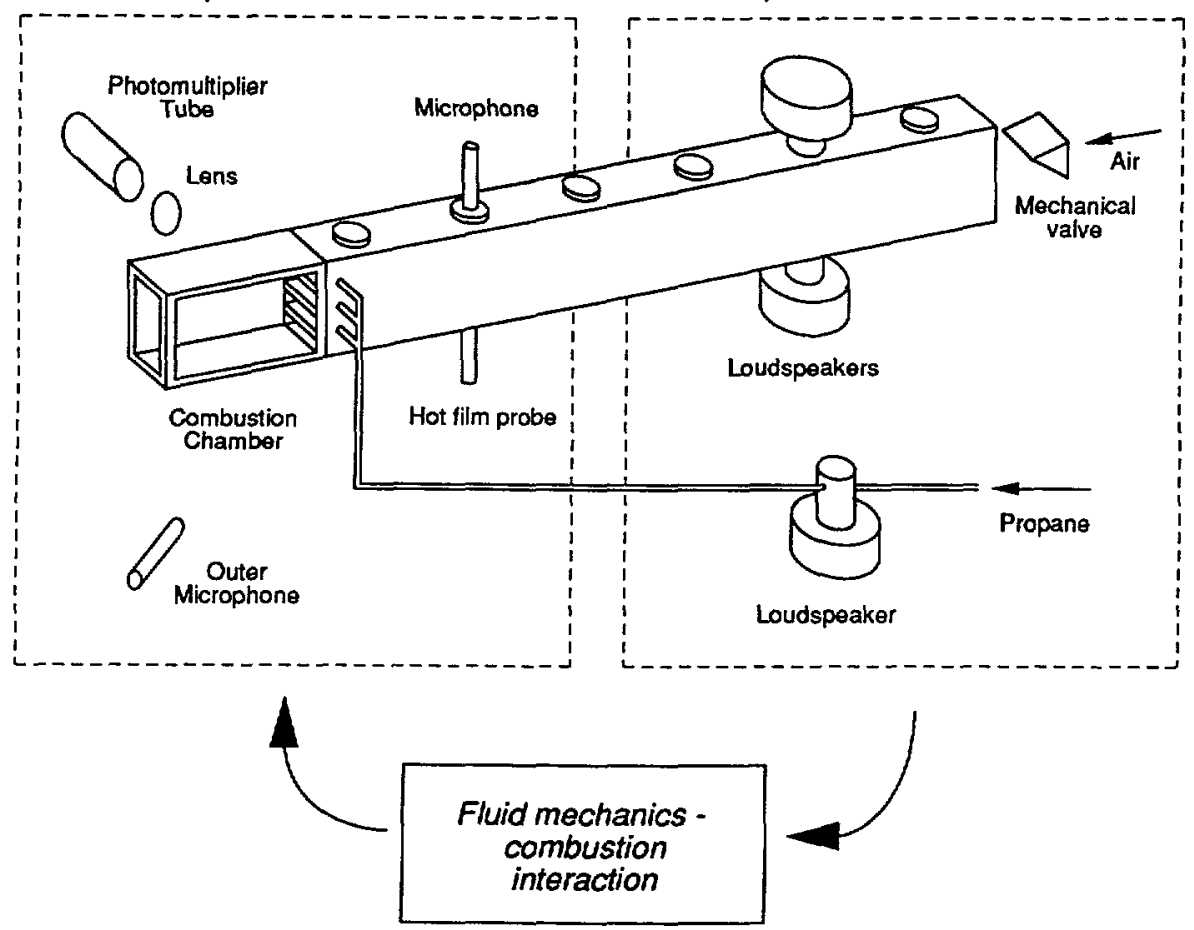

Fig. 5. - Schematic diagram of non-adaptive closed-loop active control.

The choices for the sensor $S$ and the excitation $E$ are multiple. Table I summarizes some of the possibilities as well as the results obtained in our laboratory with different combinations. The sensor may be a microphone recording pressure fluctuations, or a photomultiplier tube measuring the light emission intensity from free radicals present in the reaction zone (for 
Table I. - Comparison of different active control systems. The combustor operating conditions correspond to point $\mathrm{B}$ of figure 2 and the transfer function used in the control loop is the simple delay and amplification function in all cases.

\begin{tabular}{|l|l|l|l|c|c|c|}
\hline \multicolumn{1}{|c|}{ Output } & \multicolumn{1}{|c|}{ Input } & \multicolumn{1}{|c|}{ Sensor } & $\begin{array}{c}\Delta \phi \\
\text { (Degrees) }\end{array}$ & $p_{\min } / p_{0}$ & $\begin{array}{c}\text { Noise } \\
\text { reduction }\end{array}$ & $\begin{array}{c}W_{\min } \\
\text { (Watts) }\end{array}$ \\
\hline direct & pressure & microphone & 140 & 0.3 & $95 \%$ & 0.045 \\
direct & $\mathrm{C}_{2}$ emission & photomultiplier & 120 & 0.4 & $81 \%$ & 0.020 \\
direct & velocity & hot film probe & 140 & 0.6 & $54 \%$ & 4 \\
indirect & pressure & microphone & 130 & 0.3 & $95 \%$ & 0.004 \\
indirect & $\mathrm{C}_{2}$ emission & photomultiplier & 120 & 0.3 & $95 \%$ & 0.007 \\
indirect & velocity & hot film probe & 130 & 0.3 & $95 \%$ & 0.350 \\
\hline
\end{tabular}

- $\Delta \phi \quad$ represents the range of time delays compared to the oscillation frequency (phase margin) which will give reduced combustion oscillation,

- $p_{\mathrm{m} \text { n }}$ is the noise obtained with the control system on

- $p_{0}$ is the noise obtained without control

- $p_{\text {arr }}$ is the noise obtained for the cold flow (compressor and turbulent noise)

- The noise reduction is computed by : $\left(1-p_{\mathrm{mm}} / p_{0}\right) /\left(1-p_{\mathrm{arr}} / p_{0}\right)$

- $W_{\min }$ is the power consumption of the system after optimal control is obtained.

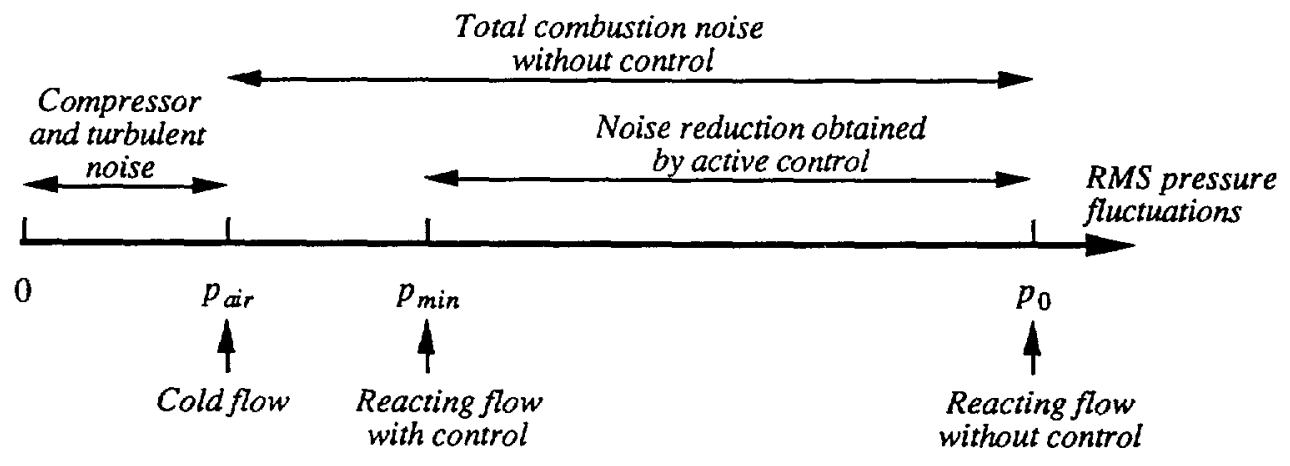

hydrocarbon flames one may study $\mathrm{C}_{2}, \mathrm{CH}$, or $\mathrm{OH}$ radicals), or a hot film probe sensing velocity fluctuations upstream of the flames. It is generally difficult to place a probe in the downstream flow because of the high temperatures existing in that region, but certain microphone systems may be plugged on the combustor walls.

The transfer function $F$ does not appear to be as critical for combustion instabilities as it is for « anti-sound " applications (Ffowcs-Williams 1984). We have used a simple transfer function corresponding to signal delay and amplification :

$$
F(s)=G \mathrm{e}^{-\tau s}
$$

where $\tau$ is a variable delay time, $G$ is a variable gain and $s=i \omega$. This particular transfer function $F$ can easily be implemented with an analog BBD delay line and an amplifier. This type of controller cannot suppress all instability modes. Since it is defined with a single delay time, it is best-suited to controlling oscillations featuring only one time scale, i,e. harmonic oscillations. In practice, this transfer function is applicable for oscillatory regimes featuring 
spectral densities where one single peak is predominant. It turns out that a large number of instability modes belong to this category.

One expects the transfer function to be adjusted as the operating conditions of the combustor are changed. For instance, as the air flow rate is increased, it is found that the optimal delay time $\tau$ has to be slightly decreased to achieve optimal control. Nevertheless, the control system is sufficiently robust that the same transfer function may be used for all operating conditions.

An important difference between the diverse configurations that may be used is the choice of the excitation device $E$. We have limited our work to acoustical excitation, although other choices are possible. For instance, Bloxsidge et al. (1988) have used mechanical valves to modulate the fresh gas flow rate in a premixed burner. More recently, Langhorne et al. (1988) have used pulsed injection of additional fuel to stabilize a laboratory reheat channel. Raghu and Sreenivasan (1987) have successfully implemented different excitation methods based on periodic heat, mass or force addition.

The actuator system may be mounted in the duct where the flame is anchored (which we will call « direct control ») or on the fuel feeding line (which we will call « indirect control»). Most recent studies have been performed with direct control (Dines 1984, Heckl 1985, Bloxsidge and Langhorne 1986, Lang et al. 1987). Direct control systems are very similar to « anti-sound "systems and appear to be a natural choice for premixed combustors. Direct control acts upon the acoustic field in the duct where the flame is stabilized, and can be viewed as a means of modifying the acoustic end impedance of the channel and consequently the energy balance of acoustic waves within the system (see for example Bloxsidge and Langhorne 1988, Lang et al. 1987 for an analytical description of this mechanism). For nonpremixed systems, the situation is quite different and Poinsot et al. (1989b) suggest that indirect control should be considered first. Indirect control acts on the fuel flow rate only. It modulates the amount of fuel injected into the combustor and accordingly, the heat release rate. The advantage of indirect control is that the perturbed flow rate is smaller $(1 / 25$ of the air volume flow rate for a stoichiometric proportion of propane), and therefore much less energy is required.

We have tested direct and indirect control on the turbulent combustor described in sections 2 and 3 . As shown in figure 5, for direct control we have used a pair of driver units mounted on the air inlet duct $1 \mathrm{~m}$ upstream of the propane injectors. For indirect control we have used a single driver unit plugged on the propane supply line, $1 \mathrm{~m}$ upstream of the injector system. Tests show that indirect control provides the best results in terms of noise reduction and of power consumption (see Tab. I).

Let us first consider an indirect control system operating at point B (Fig. 2). In this example, the sensor is a microphone placed in the inlet duct, $0.55 \mathrm{~m}$ upstream of the injection plane and the actuator is a compression driver mounted on the fuel supply line.

The effect of the active control is illustrated in figure 6 , where the time signals of the microphone and of the photomultiplier during the switch-on of the control loop are shown. Before time $t=0$, the flow exhibits strong periodic fluctuations at $270 \mathrm{~Hz}$. At $t=0$, the control system is switched on and the amplitude of all fluctuations is reduced to a level corresponding to a stable turbulent combustion in less than $50 \mathrm{~ms}$. Figure 7 presents spectral densities of the pressure and heat release signals with and without active control. The indirect AIC method reduces the level of the fundamental instability peak by almost $30 \mathrm{~dB}$. It also suppresses the flapping motion of the flames caused by the instability.

Figures 8 and 9 show the effect of active control on the RMS acoustic pressure as a function of the amplifier gain $G_{\mathrm{a}}$ and the delay time $\tau$ used in the control loop. The control is optimized by varying these two parameters. For a given controller input signal, the amplifier gain $G_{\text {a }}$ determines the amplitude of the perturbation sent back to the combustion system via 

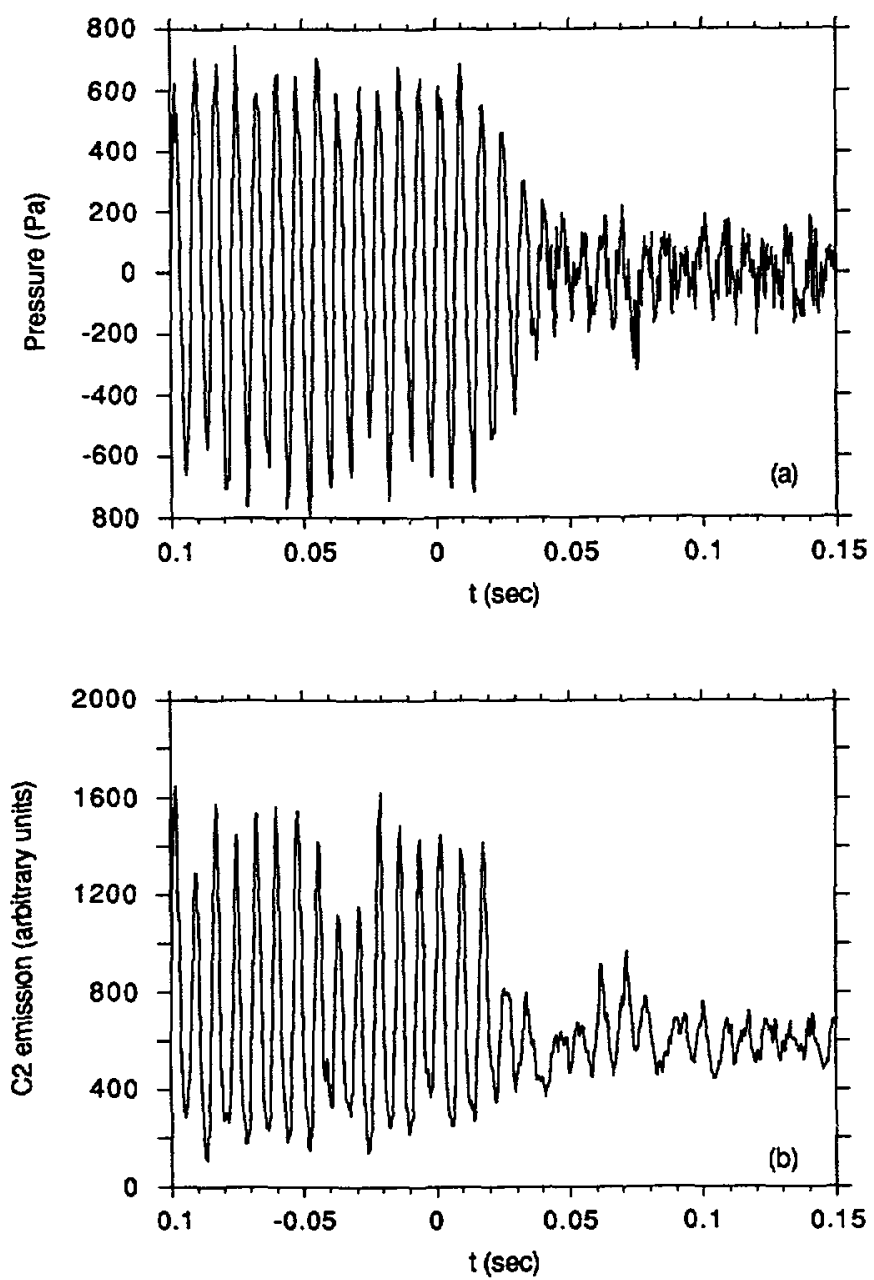

Fig. 6. - Time variations of the microphone (a) and photomultiplier (b) signals during an indirect active instability control experiment. The control system is activated at time $t=0$. Here the pressure is measured $0.35 \mathrm{~m}$ upstream of the propane injection plane and the photomultiplier detects the global $\mathrm{C}_{2}$ emission from the combustor.

the driver unit. ( $G_{\mathrm{a}}$ is proportional to the gain $G$ of the transfer function, with the proportionality constant simply being the ratio of the voltage responses of the sensor and actuator.) For small gains the control system has little effect on the fully established oscillations (this initial oscillatory state is represented in Figs. 8 and 9 by the dashed line at pressure $p_{0}$ and corresponds to the operating conditions of point B of Fig. 2). For large gains, the perturbation sent back to the system is greater than the original, so that the system becomes violently unstable, leading to extinction. In figure 8 this occurs for a gain $G_{\mathrm{a}} \sim 13$. For the constant delay time used for these measurements, gains between 5 and 12 provide an optimal control, reducing the $\mathrm{rms}$ pressure level almost to the value $p_{\text {air }}$, which corresponds to the turbulent noise level of the air supply in the absence of combustion.

At this point it is important to examine the effect of initial conditions on the AIC system performance. With a suitable preselected value of the delay time, a gain greater than a 

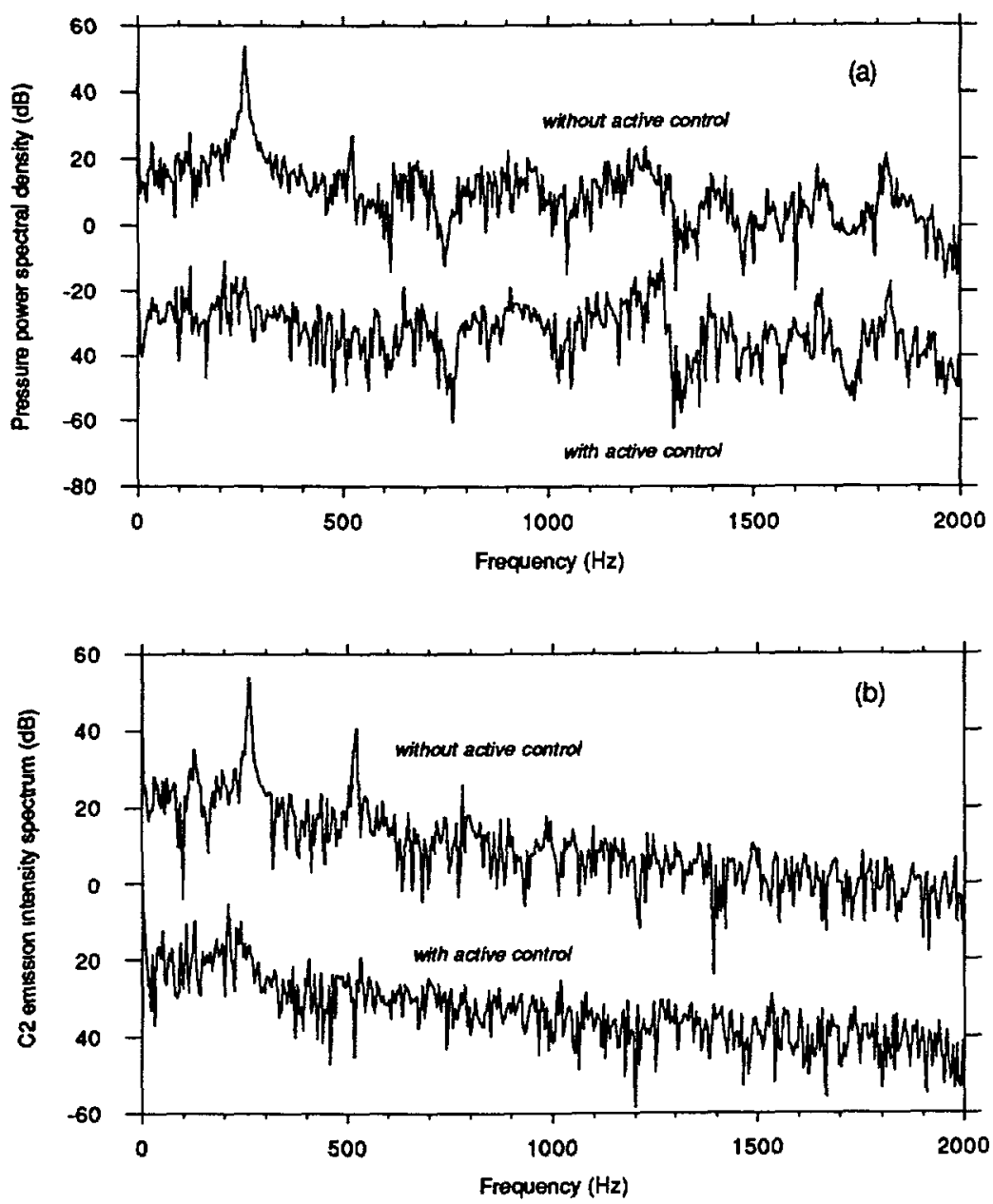

Fig. 7. - Pressure (a) and $C_{2}$ radical emission (b) spectra with and without active control. The spectra corresponding to controlled combustion oscillations have been displaced downward by $40 \mathrm{~dB}$ for clarity.

threshold value $G_{1}\left(G_{1} \sim 5\right.$ in Fig. 8$)$ is required to enable maximum noise reduction as soon as the active control is activated. This may require a high gain because the system has to work against strong initial oscillations. But once the flame is controlled, the gain can be reduced to a value $G_{2}$ while still maintaining the same level of control. This is a basic difference between instability control and sound suppression applications, because the latter require a cancellation signal with an amplitude of the same order as the original. The AIC system suppresses the noise source itself (the flame oscillations) and requires little energy to prevent the oscillations from growing again.

For an AIC gain greater than $G_{1}$, the delay $\tau$ is the most important parameter. Figure 9 indicates that the amplitude of the instability is reduced for values of the time delay between limits $\tau_{1}$ and $\tau_{2}$. Outside of this range the AIC system acts as an excitation device and the instability is amplified instead of being damped. The combustion region is then set into violent pulsations which lead eventually to extinction of one of the injectors.

The delay can be expressed relative to the period of the oscillations by introducing a phase shift parameter $\phi=2 \pi f_{0} \tau$, where $f_{0}$ is the oscillation frequency. The difference 


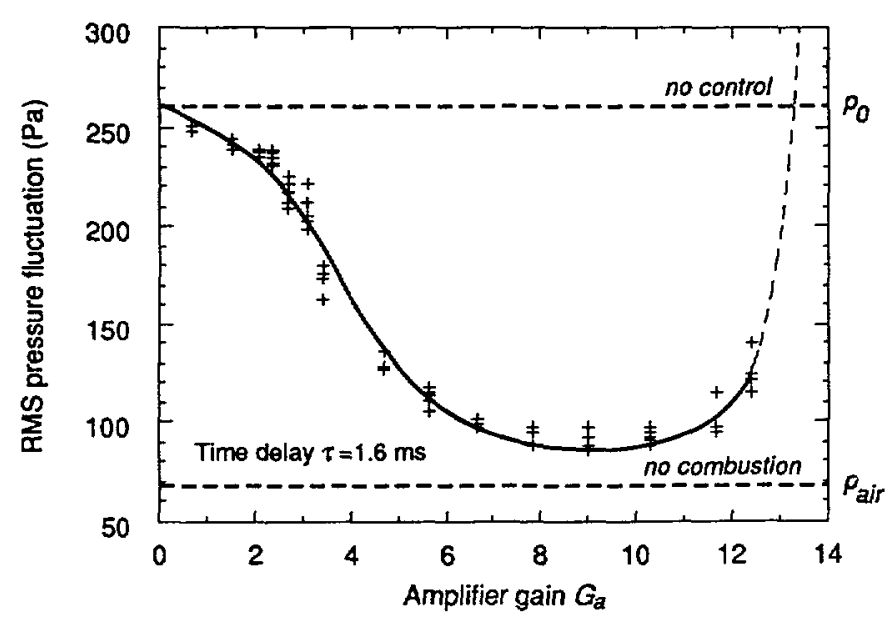

Fig. 8. - Root mean square pressure fluctuations during actively-controlled combustion, as a function of the gain parameter. The pressure is measured in the air inlet duct $0.55 \mathrm{~m}$ upstream of the fuel injectors and the flow conditions in the combustor correspond to point $\mathrm{B}$ of figure 2 . The noise level corresponding to uncontrolled combustion and the natural noise level in the system are indicated by the dashed lines.

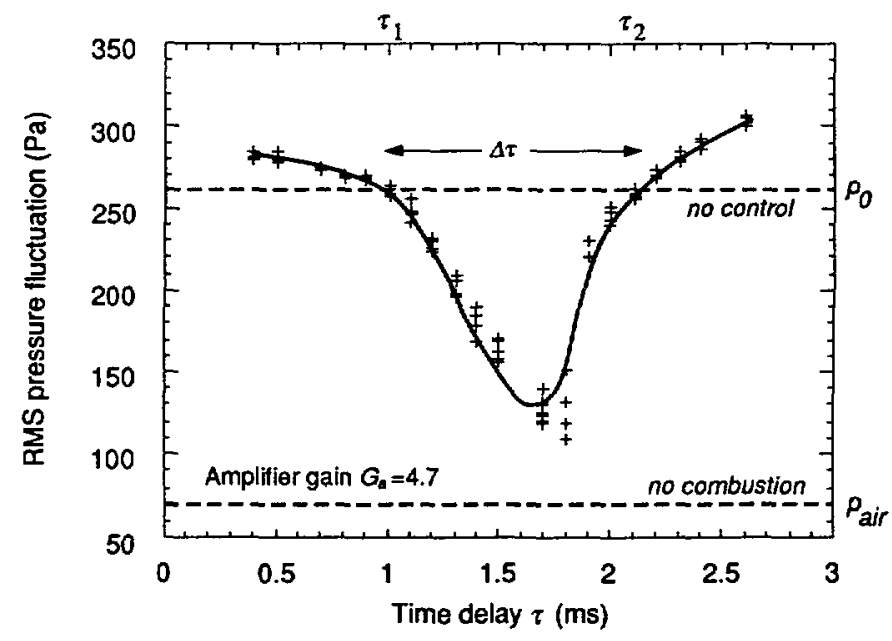

Fig. 9. - Root mean square pressure fluctuations during actively-controlled combustion, as a function of the time delay parameter. The pressure is measured in the air inlet duct $0.55 \mathrm{~m}$ upstream of the fuel injectors and the flow conditions in the combustor correspond to point $\mathbf{B}$ of figure 2 . The noise level corresponding to uncontrolled combustion and the natural noise level in the system are indicated by the dashed lines.

$\Delta \phi=\phi_{2}-\phi_{1}$ constitutes the phase margin of the AIC system (Franklin et al. 1986). The larger this range, the more robust the system. This quantity is of course a function of the gain parameter, but is virtually independent of $G$ over a large domain and only diminishes for excessively small or large gains. For a laminar burner, Lang et al. (1987) report maximum phase margins of about $100^{\circ}$ and give a theoretical estimate of $180^{\circ}$. As seen in table $I$, we find 
values close to $130^{\circ}$ for all the control systems tested on our rig. Estimating the different delay times introduced by the feedback loop and by the combustor itself is beyond the scope of this paper. However it is clear that the absolute values of the phases $\phi_{1}$ and $\phi_{2}$ or the corresponding delay times $\tau_{1}$ and $\tau_{2}$ could be used to collect some information related to the characteristic times which determine the behavior of the reacting flow. This idea is exploited by Bloxsidge et al. (1988) and constitutes another potential application of active control studies.

Let us now return to table I which presents the performance parameters for different control configurations when applied to the turbulent combustor operating under the same conditions (those of point B in Fig. 2a). Here, in order to compare the different systems, we introduce the ratio $p_{\min } / p_{0}$ to quantify the maximum noise reduction achieved by the AIC system, where $p_{\min }$ is the minimum rms pressure fluctuation obtained with active control (with optimal delay and gain values), and $p_{0}$ is the rms level without control. Also shown is $W_{\text {min }}$, defined as the electrical power output of the AIC system when it achieves the greatest reduction of the combustion noise. Without combustion, the compressor providing the air flow produces a noise level of $p_{\text {air }} / p_{0}=0.26$. The combustion noise reduction $\left(1-p_{\mathrm{m} n} / p_{0}\right) /\left(1-p_{\text {air }} / p_{0}\right)$ produced by active control is also given in table I. It is clear that the AIC system can virtually eliminate resonant combustion instability noise (which contribute to about $95 \%$ of the combustion noise without control), leaving only blower and turbulent broad-band combustion noise (about $5 \%$ of the noise without control).

The performance obtained with indirect control is superior to that with direct control in terms of noise reduction and power efficiency. Using the reaction rate or the inlet acoustic pressure signal as AIC input seems roughly equivalent. It is less effective to use the air velocity signal as input to the controller. The hot film probe signal contains many frequency components corresponding to local turbulent fluctuations that are not related to the instability. These frequency components are amplified by the control system without contributing to the control of the instability.

We have up to now focused on the sound pressure levels to characterize the combustion system response when AIC is applied. One may also consider the effect of the control on the heat release rate in the combustor. Plots of the mean and rms fluctuations of the photomultiplier signal (Fig. 10) show qualitatively how the AIC system alters the combustion intensity under different operating conditions. The propane flow rate is the same as that of point $\mathrm{B}$ and the air flow rate is varied. The control loop parameters $G$ and $\tau$ were slightly adjusted to optimise the control as the air flow rate was changed in these measurements. The zero level in the two plots corresponds to the light intensity in the absence of combustion. Figure $10 \mathrm{a}$ shows the root-mean-square values of the $\mathrm{C}_{2}$ emission fluctuations. For operation without active control, two regions of large amplitude combustion oscillations corresponding to the 190 and $270 \mathrm{~Hz}$ modes of figure $2 \mathrm{a}$ are seen. With control, the fluctuations are almost eliminated and the operating range of the combustor is significantly extended. Furthermore, the finely-dashed curve in the figure confirms the complex behavior presented in figure $2 \mathrm{a}$. In particular, it shows the continued presence of combustion oscillations (at a reduced amplitude) after extinction of the bottom flame pair (air flow rate $>100 \mathrm{~g} / \mathrm{s}$ ), and the sudden decrease of oscillation amplitude after the second extinction (air flow rate $>120 \mathrm{~g} / \mathrm{s}$ ), leaving only the top flame pair. A closer inspection of the air flow rates reveals that data of figure $2 \mathrm{a}$ and figure 10 do not correspond exactly. Data were taken several months apart, during which the exact experimental conditions were slightly modified. However, the qualitative behavior of the combustor remains the same.

Figure $10 \mathrm{~b}$ displays the mean $\mathrm{C}_{2}$ emission from the chamber. The 190 and $270 \mathrm{~Hz}$ instabilities enhance the total heat release in the combustor. These instability modes are associated with large flame front motions and the periodic intense mixing generated by small- 


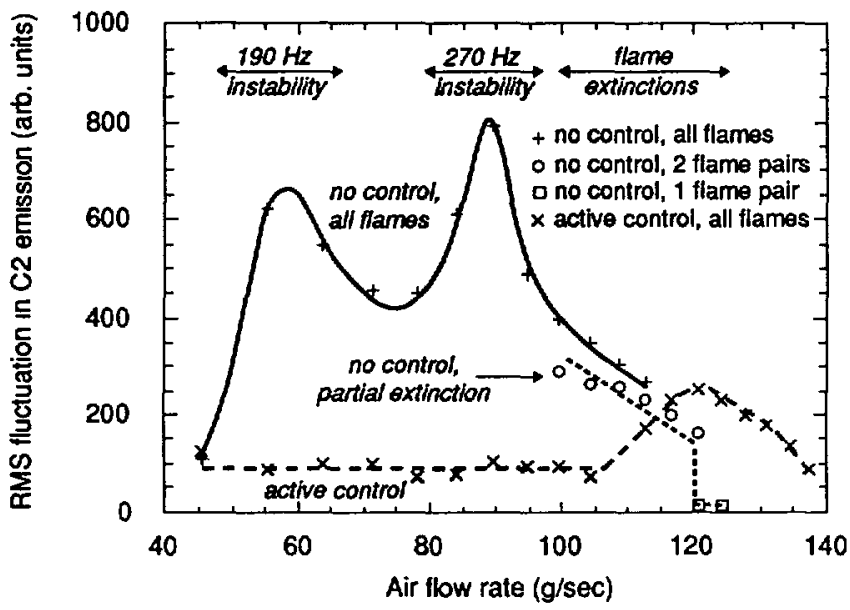

(a)

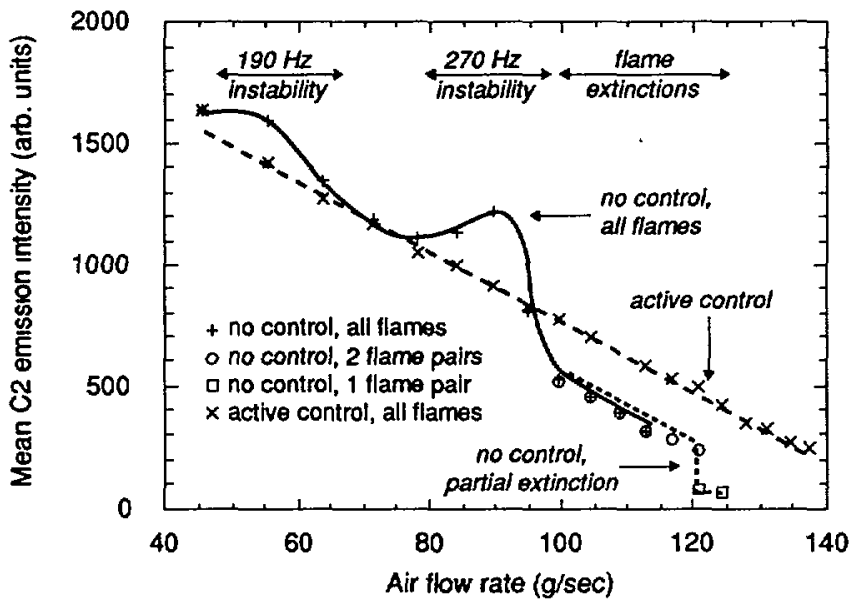

(b)

Fig. 10. - Variation of the root-mean-square fluctuations (a) and the mean (b) of the global $\mathrm{C}_{2}$ radical emission signal, with and without control. The total propane flow rate was $0.61 \mathrm{~g} / \mathrm{s}$, and the active control parameters were slightly adjusted to optimise the control as the air flow rate was increased. The zero level corresponds to complete extinction of the combustor.

scale turbulence created during the flame interactions increases combustion. Under these circumstances, application of AIC reduces the net heat release by suppressing the flame front interactions. However, for high air flow rates, AIC enhances the combustion. In this case, the fully established oscillations (without control) are responsible either for periodic localized extinctions or periodic moments of reduced burning. In suppressing the oscillation cycle, the control system in this instance increases the net heat released in the combustor.

To sum up this section, under application of the AIC system, the stability and extinction domains of the combustor are strongly altered. Figure 2 shows two operating charts for the combustor, one for uncontrolled operation (Fig. 2a) and one where the combustion is actively-controlled (Fig. 2b). The 190 and $270 \mathrm{~Hz}$ instabilities are completely suppressed by the active control and the instability-related flame extinctions eliminated. The extinction line at very high air flow rates is not associated with an instability and is unchanged by control. 
This line is presumably related to a lean blow-off mechanism involving the flame stabilization zones. The resulting operating diagram for actively-controlled combustion therefore consists of only two regions : a large oscillation-free region where the burning is smooth and a region where there is no combustion. The AIC system significantly increases the practical operating domain of the combustor by eliminating extinctions caused by combustion oscillations.

The choice of points $B, D, E$ and $F$ of figure 2 which will be used in sections 5 and 6 can now be understood. At point $B$, the uncontrolled flow is characterized by the $270 \mathrm{~Hz}$ instability mode whereas it is stable when the control system is operated. Starting from a controlled flow at this point and switching off the control system, one may conveniently study the initiation of the $270 \mathrm{~Hz}$ mode (Sect. 5). At points D, E or F, the uncontrolled flow cannot sustain all three flame pairs, whereas it can with control. By switching-off the control system at points D, E or F, one may examine extinctions caused by combustion oscillations (Sect. 6).

\section{Initiation of turbulent combustion instabilities.}

5.1 TIME HISTORY OF INSTABILITY INITIATION. - The AIC system is now applied to the combustor operating under the conditions corresponding to point B in figure 2a. Breaking the control loop triggers the growth of an instability mode at a frequency of $270 \mathrm{~Hz}$. Figure 11 displays the time evolution of the pressure and emission signals during instability growth.

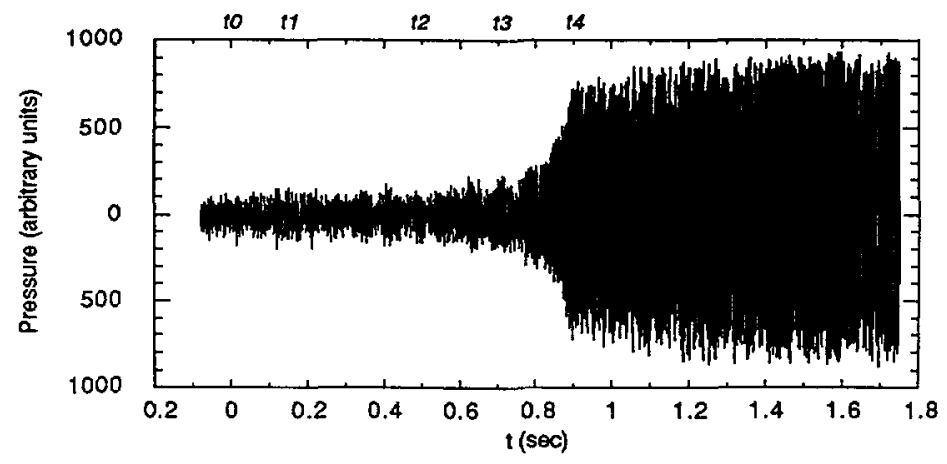

(a)

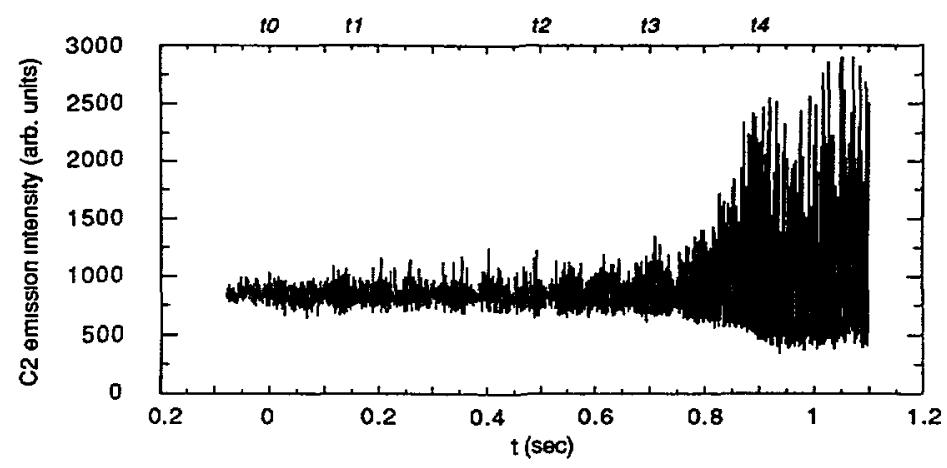

(b)

Fig. 11. - Time history of the microphone (a) and photomultiplier (b) signals during instability initiation. The pressure is measured in the air inlet duct $0.65 \mathrm{~m}$ upstream of the fuel injection plane and the photomultiplier detects the global $\mathrm{C}_{2}$ emission from the combustion chamber. The active control is removed at time $t=0$. 
Before time $t_{0}=0$, the system is stabilized with optimal gain and time delay parameters. At time $t_{0}$, the AIC system is switched off and the instability is free to grow. The instability growth between time $t_{0}$ and $t_{2}=0.5 \mathrm{~s}$ is slow, indicating that the linear instability gain is small. At time $t_{3}=0.7 \mathrm{~s}$, both signal amplitudes increase faster and a limit cycle is obtained after time $t_{4}=0.9 \mathrm{~s}$. This behavior is typical of a standard supercritical Hopf bifurcation in which an initially stable solution becomes unstable and leads to a limit cycle oscillation.

It is found that the limit cycle is established when the minimum of the heat release signal reaches a minimum, corresponding to reduced combustion. This observation suggests that the growth of the oscillation amplitude is limited by a periodic local extinction of the flames and determined by the saturation of combustion rate oscillations and not by acoustic losses.

5.2 SPECTRAL ANALYSIS AND HIGH-SPEED CINEMATOGRAPHY OF INSTABILITY INITIATION. Active control has already been used to study combustion instability initiation by Poinsot et al. (1989b). We will briefly present some new results obtained in the same configuration here because they are needed to understand extinction mechanisms and also provide an example of active control application to combustion instability studies.

Figure 11 displays the time variations of the microphone and photomultiplier signals during the instability initiation. Figure 12 presents the time variations of the spectral amplitudes of the fundamental mode $(270 \mathrm{~Hz})$ and its harmonic frequencies for the microphone and photomultiplier signals during the same period.

High-speed Schlieren visualizations and nonlinear spectral analysis of pressure and heat release signals during instability initiation (Fig. 12) suggest that the complete instability growth may be split into three global processes:

(1) A linear process (from $t=t_{0}$ to $t=t_{1}$ ) called induction phase during which the amplitude of the fundamental frequency (in the $235-290 \mathrm{~Hz}$ range in Fig. 12a) increases linearly. Schlieren visualization reveals that the flame sheets are only submitted to breathing motions during this period but that their internal turbulent structure appears to unaffected. This phase may be studied with linear models and without taking turbulence modifications into account.

(2) A transition process called modulation phase which corresponds to $t=t_{1}$ to $t=t_{2}$ and where the flame sheet interactions induce modifications of the inner structure of the sheets but in an intermittent way. Because this interaction is intermittent, no real lock-in mechanism takes place yet. The flow is in a metastable state which will end as soon as the flame break-up process and the associated pulsating combustion lock in with the acoustic oscillations.

(3) A nonlinear resonant process (nonlinear phase) after $t=t_{2}$, which effectively induces combustion instability. Once the acoustic waves lock with the flame sheet motions, the interaction of the flame sheets become stronger at each cycle until the limit cycle described in figure 3 is reached.

This scenario already in Poinsot et al. (1989b) merits the following additional remarks :

- The phases described above have been identified in every initiation experiment performed. Only the induction and modulation phase durations showed variations.

- Time history data like that displayed in figure 12a may be used to check theoretical linear models. The induction phase shows a growth rate of the fundamental instability mode of roughly $3.6 \mathrm{~s}^{-1}$

- Slight frequency shifts are identified during the instability growth. The fundamental mode frequency varies from $230 \mathrm{~Hz}$ during the induction phase to $270 \mathrm{~Hz}$ at the limit cycle. This shift is a characteristic feature of nonlinear systems and may be a consequence of the dependence of the combustor outlet acoustic boundary condition on the oscillation amplitude, as suggested by Heckl (1985). 


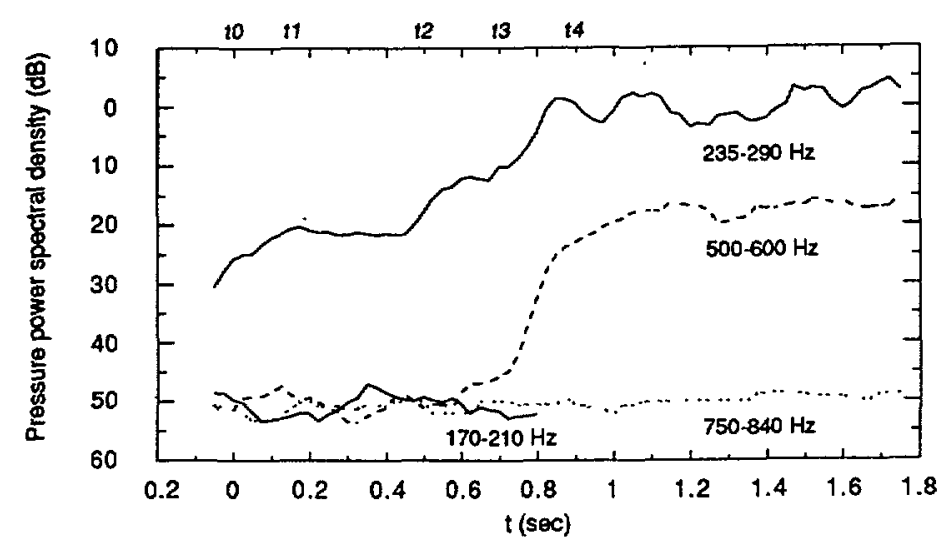

(a)

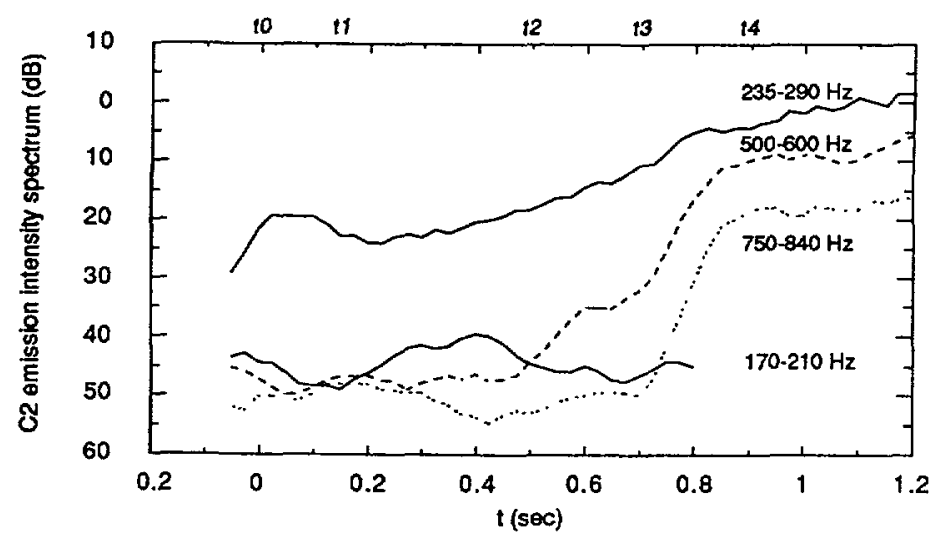

(b)

Fig. 12. - Frequency histories of the microphone (a) and photomultiplier (b) signals during instability initiation. The active control is removed at time $t=0$, and combustion oscillations at the fundamental frequency begin to increase in amplitude immediately. The harmonic content of the signals does not increase until later during the initiation process $\left(t>t_{3}\right)$, and the limit cycle of the combustion oscillations is achieved after time $t=t_{4}$.

- Because all flame pairs oscillate in phase as soon as the control system is switched off, the origin of the initial oscillations is acoustic in nature. During the induction phase, the flames respond to forcing by low frequency acoustic modes of the ducted system and oscillations are slowly amplified. This does not mean that dynamic flow effects are negligible during the first instants of initiation. However. the flame response is controlled by acoustic plane waves which constitute the primary source of the flow oscillations.

- Turbulence effects appear in the modulation phase when the flame sheets begin to interact and to modify the local turbulent heat release rate.

- The effective combustion instability begins during the nonlinear phase when the flame sheets interact at each cycle. The instability would not grow beyond the modulation phase without the small scale mixing and the corresponding heat release pulse generated at each cycle when the flame fronts collide together. The reaction pulse caused by this collision event feeds a significant amount of energy back to the acoustic field. Locking is complete and the oscillation amplitude increases rapidly until nonlinear saturation is achieved. 
These results suggest that large amplitude combustion instabilities (such as those obtained in the nonlinear phase) are produced when the turbulent field is significantly modified by the flame oscillations or equivalently when the turbulent reaction rate becomes a sensitive function of the flame oscillations. This is consistent with the nonlinear model of Poinsot and Candel (1988) which shows that no combustion instabilities arise in a turbulent premixed combustor when flame sheets oscillate without changes of their inner structure. It also confirms previous experiments demonstrating the importance of small scale turbulence production and combustion acceleration in the instability mechanism. Such pulsating combustion phenomena may be achieved in turbulent flows by flame front interactions, like in the present study or in the work of Poinsot et al. (1987), or by flame impingement on a solid boundary (Sterling and Zukoski 1987, Yu et al. 1990).

\section{Extinction due to combustion instabilities.}

As described in section 4, the control system may also be used to operate beyond the normal extinction limits of the system, while still maintaining stable combustion. Under lean operating conditions, such as those represented by points D or F in figure $2 a$, breaking the control loop triggers an extinction on-demand. This extinction may be partial (one or two flame pairs) or complete. We will present only partial extinction cases here.

The mechanism of instability growth under these operating conditions is the same as that described in section 5 , but this growth is much more rapid. It is more difficult to separate the different phases involved. One important difference here is that the growth of the instability is interrupted by a flame extinction before the anticipated limit cycle is obtained. A new limit cycle is established at a lower amplitude corresponding to the oscillation of a reduced number of flames.

The phenomenology associated with the extinctions may be illustrated by the three different cases shown in figure 13 . The global $\mathrm{C}_{2}$ emission through the combustor windows is plotted as a function of time together with the running means of these signals, which are shifted above the original signals for clarity. The running mean is obtained by averaging the instantaneous photomultiplier output $I(t)$ with a Gaussian filter. The averaging period (corresponding to the full width of the distribution) has a fixed value of $N \Delta t=30 \mathrm{~ms}$. The vertical scale represents the instantaneous photomultiplier signal and its origin corresponds to the ambient light level with no combustion.

The control loop is deactivated at time $t_{0}=0$. In the case shown in figure $13 \mathrm{a}$, the operating conditions correspond to point $\mathrm{D}$ in figure $2 \mathrm{a}$. The delay time before the appearance of periodic oscillations lasts $22 \mathrm{~ms}$ and an oscillation at $290 \mathrm{~Hz}$ grows linearly for about $36 \mathrm{~ms}$. This growth is terminated by an abrupt drop in the signal level corresponding to the extinction of the bottom flame pair. This event is clearly identified in the running mean trace which features a drop to approximately two thirds of its original value at $t_{1}=58 \mathrm{~ms}$. The instantaneous signal shows that after time $t_{1}$, a limit cycle is established which corresponds to the oscillatory burning of the remaining two flame pairs. One also notices that after time $t_{1}$, there appears to be a rough lower cut-off limit to the signal level - a saturation level slightly greater than zero. This saturation level is associated with the near-extinction of all three flame pairs. It indicates that during each instability cycle, there is a moment where the flames are only barely alight. The limit cycle in this example is clearly established as a result of combustion limits rather than acoustic losses.

In other instances, the system may respond differently. In the example of figure $13 \mathrm{~b}$ (Point E in Fig. 2a) «extinction » of one flame pair takes place at $t_{1}=50 \mathrm{~ms}$ and the light intensity then goes through a series of large modulations. The lower values of the instantaneous signal again come close to the zero corresponding to no combustion, while the maximum oscillation 

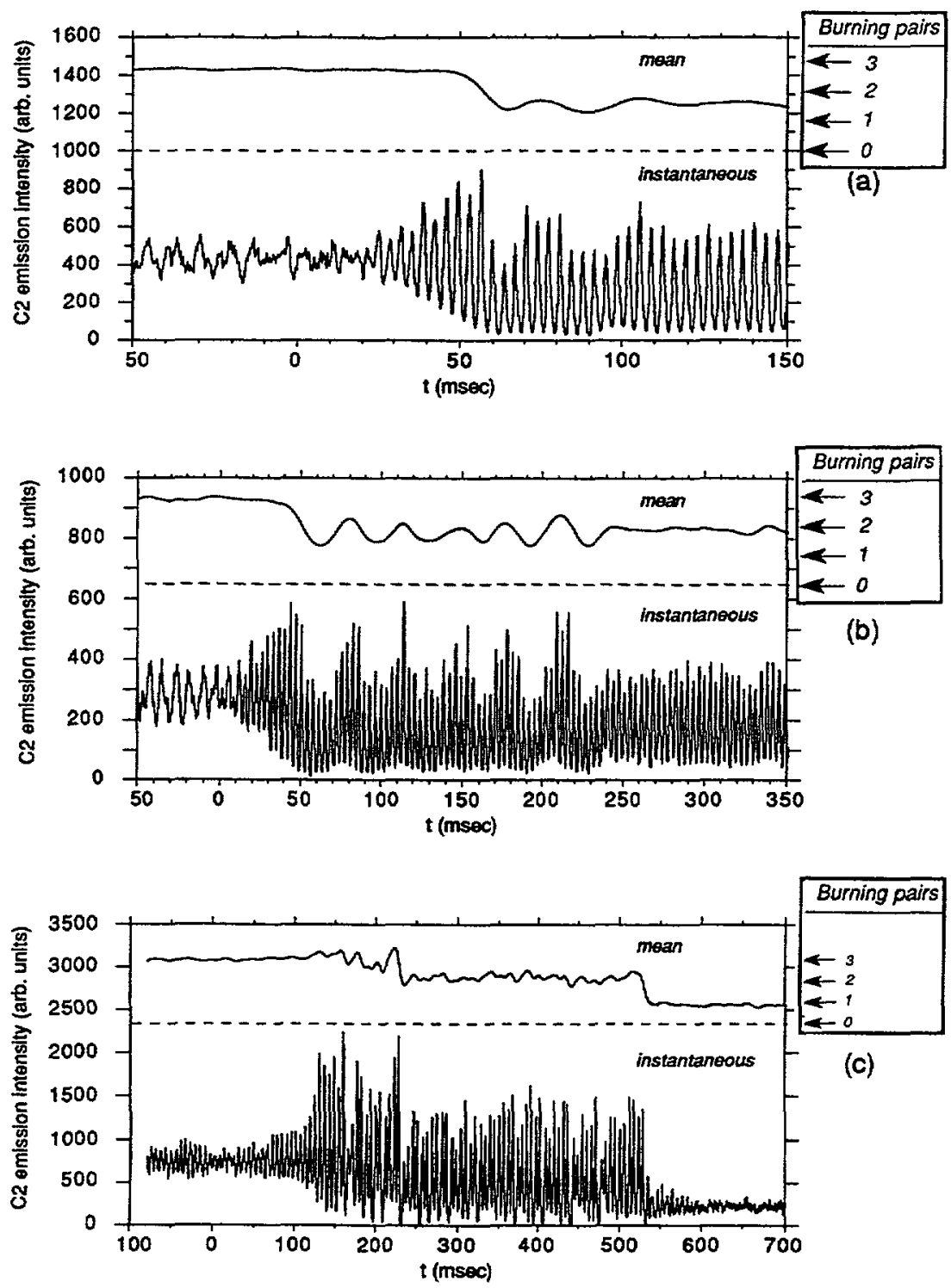

Fig. 13. - Time variation of the global $\mathrm{C}_{2}$ emission during extinction. The control system is deactivated at time $t=0$, after which the combustion oscillation grows until a flame extinction is induced. The vertical scale corresponds to the instantaneous emission intensity. The mean emission curves are shifted upward for clarity and the zero level for these displaced curves is represented by the dashed line. (a) Point $\mathrm{D}$ in figure 2, $270 \mathrm{~Hz}$ mode ; (b) Point $\mathrm{E}$ in figure 2, $270 \mathrm{~Hz}$ mode ; (c) Point $\mathrm{F}$ in figure 2, $190 \mathrm{~Hz}$ mode.

amplitude regains values close to the amplitude level prevailing at the extinction time $t_{1}$. The mean value of the signal is also modulated with a period of about $30 \mathrm{~ms}$. These observations indicate that one of the flame pairs undergoes a cyclic «extinction» and « reignition » at a frequency close to $30 \mathrm{~Hz}$. This reignition period is governed by the time required for the amplitude to grow from a low level corresponding to the near extinction of one flame pair to the high level characterizing three well burning flame pairs. The « relaxation 
oscillator »-type behavior observed in this case cannot be sustained for long times and is terminated at $t_{2}=240 \mathrm{~ms}$ when the struggling flame pair is definitively extinguished. Again the mean intensity of emission from two flame pairs is approximately two thirds of the intensity before the extinction. The Schlieren photographs in figure 14 (taken during another extinction event under similar operating conditions) show this phenomenon of flame quenching and reignition. The time interval between each consecutive image is $1.5 \mathrm{~ms}$. Comparing the flow field of figure $14 \mathrm{~g}$ with those of $14 \mathrm{a}, 14 \mathrm{~d}$ and $14 \mathrm{k}$, one sees that the flames interact further downstream after a period of diminished combustion of the upper flame pair.

Figure 13c presents an example of extinctions which can occur as a result of the $190 \mathrm{~Hz}$ instability mode (Point $\mathrm{F}$ in Fig. 2a). At $t_{1}=160 \mathrm{~ms}$ the oscillation amplitude undergoes a sudden drop, but the mean light intensity is hardly affected. A second abrupt change at $t_{2}=220 \mathrm{~ms}$ corresponds to an extinction of the flame pair behind one fuel injector, after which the mean intensity settles down at a level which corresponds to about $2 / 3$ of its initial value. The system continues to oscillate until $t_{3}=530 \mathrm{~ms}$, at which time yet another pair of flames is extinguished and the mean light level drops by yet another third of its value for $t<0$. Resonant oscillations are no longer sustained and the one remaining flame pair soon burns smoothly. Note that unlike the previous examples, the system requires about $60 \mathrm{~ms}$ to achieve a steady state after the second extinction.

These experiments show clearly that pressure oscillations are responsible for flame extinctions. This apparently simple result would have been difficult to obtain without the possibilities offered by active control : extinction takes place in a very short time and the existence of instabilities just before extinction would be difficult to detect and study without active control (for one thing, extinction takes place without generating any appreciable noise outside of the combustor). It seems that combustion instabilities may be playing a large role in controlling the operating domain of a given combustor even when no actual limit cycle is observed.

Spectral analysis shows that extinction phenomena in all cases described above take place at the end of the modulation phase defined in section 5 . It is found that the flame sheets are not able to sustain combustion when the nonlinear phase begins. This nonlinear phase is characterized by a phase-locking of the acoustic waves and of unsteady combustion. During this phase, the amplitude of the oscillations grows rapidly and leads to the disruption of flame sheets.

The most likely mechanism leading to extinction is due to two effects : (1) changes in the temperature of the recirculation zone which stabilizes the flame near the flame holders and (2) variation of stretch effects near the flame holders. Both effects are directly or indirectly controlled by the injection velocity. The following scenario of the instability and of the transition to total extinction may be proposed (Fig. 15). At a given instant of the cycle, fresh material is accumulated between the flame sheets and mixes with burnt products (Fig. 15a). The combustion of this material at a later time (Fig. 15b) has been evidenced recently using two-dimensional LIF images of $\mathrm{OH}$ radicals (not presented here) and is quite violent. It induces a strong radial flow (Fig. 15c) which has two effects : (1) it slows down the flow near the flame holder and thereby decreases the stretch imposed on the flames, issuing from the injectors and (2) it feeds burnt material into the recirculation zones and increases their temperature. Both effects enhance the capability of the flow near the flame holder to reignite : $\mathrm{OH}$ images show that during this phase (Fig. 15d) combustion is enhanced near the injectors and combustion zones seem to propagate upstream towards the injectors. In the case of limit cycles with no extinction, this reignition process is successful at each cycle. In the case of a total extinction event, this reignition process starts but is unable to proceed fast enough to be complete when the injection velocity starts growing again. This is due to a combination of 


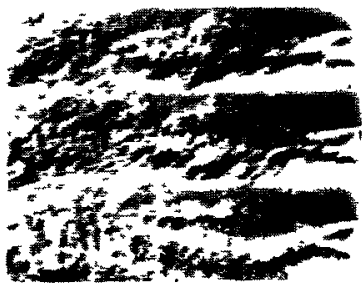

(a)

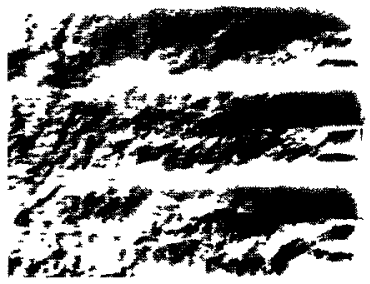

(d)

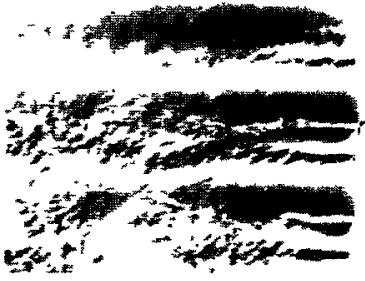

(g)

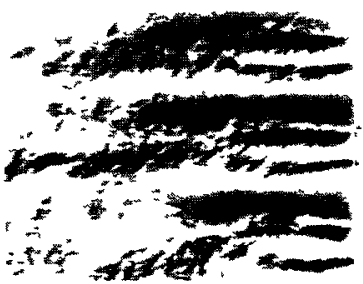

(i)

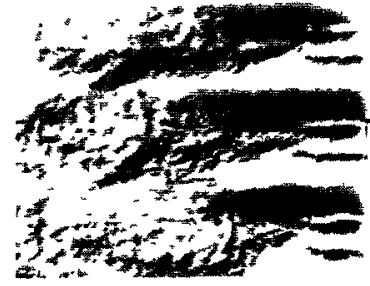

(b)

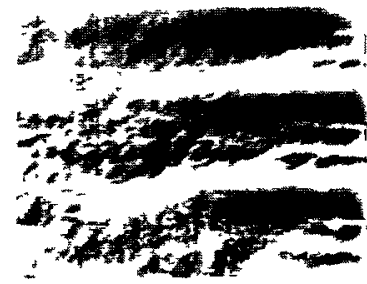

(e)

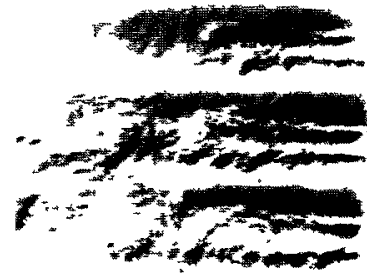

(h)

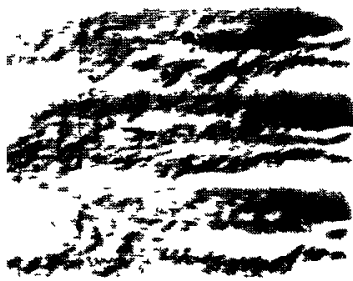

(k)

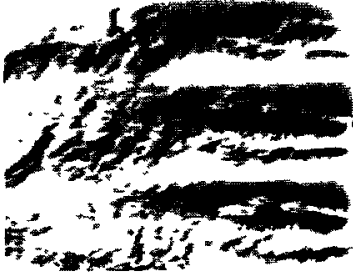

(c)

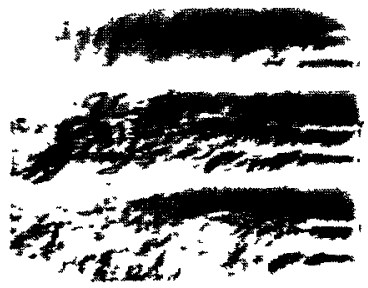

(f)

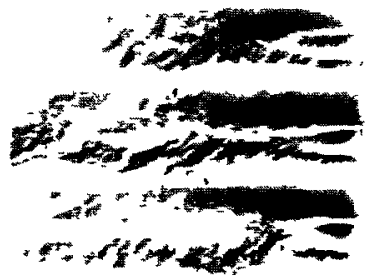

(i)

Fig. 14. - Schlieren photographs showing flame quenching and reignition during an extinction induced by the $270 \mathrm{~Hz}$ oscillation mode. Strong interaction between the flame pairs (a, b, c) leads to an almost complete extinction of the top flame pair (e). Combustion soon resumes (i), and the original burning cycle is regained $(k)$. This process ends when complete extinction of the top flame pair occurs during the cycle. The time interval between each consecutive image is $1.5 \mathrm{~ms}$. The combustor operating parameters correspond to Point $\mathrm{E}$ in figure 2.

low temperature in the recirculation zones and weak capability of these flames to sustain stretch. Both effects are controlled by the stoichiometry. A rough estimate of the stretch oscillation in this configuration gives amplitudes of the order of $1000 / \mathrm{s}$. These values are certainly large enough to induce local quenching when the local equivalence ratio is far from stoichiometric. The exact verification of this scenario would require a computation of 
(a) Fresh material is accumulated between the flame sheets and mixes with burnt products

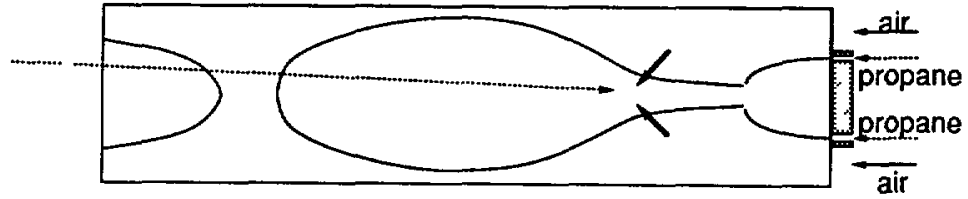

(b) This material starts reacting

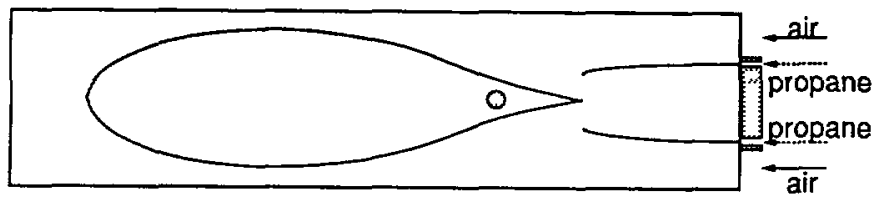

(c) A heat pulse is created by the combustion of this material. It induces a large radial flow

(d) The radial flow has two effects: (I) it slows the flow upstream of the injectors and decreases the flame stretch near the injectors

(2) it feeds the recirculation zone with burnt products and increases its temperature

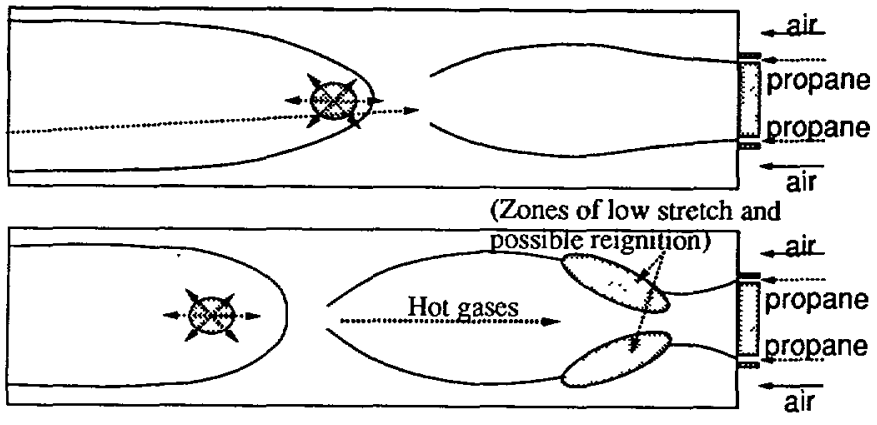

(e) If the stretch is low enough and the temperature of the recirculation zone is high enough, reignition takes place. Otherwise, total extinction is obtained (like here)

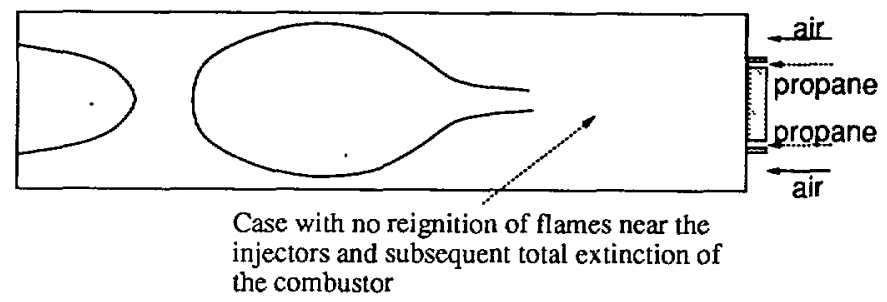

Fig. 15. - Scenario of instability leading to total flame extinction.

diffusion flames submitted to sinusoidal stretching effects and sinusoidal hot gas temperature. The effect of oscillating stretch has been investigated in (Darabiha 1991) and the effects of variable hot gases temperature in (Darabiha and Candel, 1991). However no computation of the effects of both mechanisms is available at the present time. It appears that extinction by an instability is a complex phenomenon and that active control has allowed a satisfactory insight into this mechanism.

\section{Conclusion.}

This article shows that active control is a promising investigation method for combustion instabilities. It is used in this study to suppress combustion instabilities in a multiple-flame non-premixed turbulent combustor. Different control techniques have been tested and compared. Results show that active control allows the suppression of all instability modes of the combustor, a noise reduction of combustion noise of the order of $95 \%$ and a significant extension of the operating range of the combustor. From a more fundamental point of view, it enables the study of different transient phenomena related to combustion oscillations : initiation of low frequency instability modes, and extinctions induced by pressure oscillations. 
The experiments conducted provide insights into the initial instability growth mechanism. The analysis uncovers three successive phases in the instability onset : induction, modulation and nonlinear phase. The origin of the instability is a low frequency acoustic mode of the ducted system. This mode induces a breathing motion in the flame zone (induction phase). This motion forces the different flame sheets to interact, at first in an intermittent way (modulation phase). When flames interact periodically at each instability cycle, they produce small scale turbulence, increase mixing and generate a heat release pulse. A resonant coupling between this oscillatory reaction rate and the acoustic field leads to a rapid growth of the amplitude of flame displacements and to a limit cycle (nonlinear phase). The amplitude saturation is related to fluid mechanical processes and not to nonlinear acoustic phenomena.

In this study the flame zone is initially destabilized by a low frequency acoustic mode but oscillations would not grow beyond the modulation phase without a strong fluid mechanical feedback due to the flame sheet interactions. Acoustic and fluid dynamic effects are both important, although not at the same instants. These results suggest that classifications based on definitions of « acoustic » and « hydrodynamic » (or « convective ») instabilities are too simple-minded and do not reflect the complex reality of many instability mechanisms.

Active control has also been used to investigate extinctions induced by combustion oscillations. Extinctions take place during the modulation phase, thus preventing the growth of a fully established limit cycle where all flame pairs would sustain combustion. Observations show that the response of the system during different extinction events exhibits many different forms. In some cases a flame pair extinguishes immediately and the oscillations continue at a lower intensity level. In other circumstances, final extinction of an injector occurs after a series of quenchings and reignitions. Still in other cases the combustion remains in a rough mode until successive extinctions lead to a stable regime in which only a single pair of flames subsists. The detailed explanation of these phenomena still poses a challenging research problem.

\section{Acknowledgments.}

In some of the experiments, the high speed Schlieren cinematographic system was provided and operated by M. Surget, Pequignot and Dunet from ONERA. Their help is gratefully acknowledged. The development of the combustion chamber was funded by the Societe Européenne de Propulsion. Suggestions made by the referees have been quite helpful in improving this article.

\section{References}

BarRère M. and Williams F. A., Comparison of combustion instabilities found in various types of combustion chambers, Eleventh Symposium (International) on Combustion, The Combustion Institute, Pittsburgh (1968) p. 169.

Billoud G., Huynh Huu C., Galland M. A. and Candel S., Adaptive active control of combustion instabilities, submitted to Comb. Sci. Tech. (1991).

Bloxsidge G. J. and LANGHORNe P. J., Active control of an acoustically driven combustion instability, Euromech Colloquium (1986) p. 213.

Bloxsidge G. J., Dowling A. P., Hooper N. and Langhorne P. J., Active control of reheat buzz, AIAA J. 26 (1988) 783.

CHEN C. H., Non Linear Maximum Entropy Spectral Analysis Methods for Signal Recognition (Research Studies Press, 1982).

Clavin P., Pelcé P. and He L., One dimensional vibratory instability of planar flames propagating in tubes, J. Fluid Mech. 216 (1990) 299-322.

Crocco L. and Cheng S. I., Theory of Combustion Instability in Liquid Propellant Rocket Motors (Butter worths Science Publications, London) AGARDOGRAPH Nº 8 (1956). 
Crocco L., HarrJe D. T. and ReARdon F. H., Transverse combustion instability in liquid propellant rocket motors, J. Am. Rock. Soc. 32 (1962) 366.

Crocco L., Theoretical studies on liquid-propellant rocket instability. Tenth Symposium (International) on Combustion, The Combustion Institute, Pittsburgh (1965) p. 1101.

CulICK F. E. C., Nonlinear growth and limiting amplitude of acoustic oscillations in combustion chambers, Combust. Sci. Tech. 3 (1971) 1.

CulICK F. E. C., Combustion instabilities in liquid-fueled propulsion systems, An overview, AGARD Conference Proc., CP-450 (1988).

DARABIHA. N., Unsteady behaviour of laminar counterflow hydrogen-air diffusion flames with complex chemistry, Combust. Sci. Tech. in press (1992).

DARABIHA N. and CANDEL S., The influence of the temperature on extinction and ignition limits of strained hydrogen-air diffusion flames, Combust. Sci. Tech. in press (1992).

Dines P. J., Active Control of Flame Noise, PhD Thesis (Cambridge University, Cambridge, 1984). Ffowcs-Williams J. E., Anti-sound, Proc. Roy. Soc. London A 395 (1984) 63.

Franklin G., Powell J. and EMami-NaEINI A., Feedback Control of Dynamic Systems (AddisonWesley, 1986).

Giovangigli V. and SMOOKE M., Extinction of strained premixed laminar flames with complex chemistry, Combust. Sci. Tech. 53 (1987) 23.

Gulati A. and MANI R., Active control of unsteady combustion-induced oscillation. 28th Aerospace Sciences Meeting, AIAA Paper 90-0270 (1990).

Gutmark E., PARR T., Hanson-Parr M. and Schadow K., Active shear flow control for improved combustion. 28th Aerospace Sciences Meeting, AIAA Paper 90-0454 (1990).

HECKL M. A., Active control of the noise from a Rijke tube. IUTAM Symposium on Aero and HydroAcoustics, Lyon (Springer Verlag, 1985) p. 211.

Jou W. H. and MENON S., Simulations of ramjet combustor flow fields Part II. Origin of pressure oscillations. Nineteenth Fluid Dynamics, Plasma Dynamics, and Lasers Conference, Honolulu, Hawaii, AIAA Paper 87-1422 (1987).

Kailasanath K., Gardner J. H., Boris J. P. and Oran E. S., Acoustic-vortex interactions and low frequency oscillations in axisymmetric combustors, Twenty-fifth Aerospace Sciences Meeting, Reno, Nevada, AIAA Paper 87-0165 (1987a).

Kailasanath K., Gardner J. H., Boris J. P. and Oran E. S., Acoustic-vortex interactions and low frequency oscillations in axisymmetric combustors, J. Propulsion 3 (1987b) 525.

KAY S. M. and MARPLE S. L., Spectrum analysis, A modern perspective, Proc. IEEE 69 (1981) 1380.

Keller J. O., Vaneveld L., Korschelt D., Hubbard G. L., Ghoniem A. F., Daily J. W. and OPPENHEIM A. K., Mechanisms of instabilities in turbulent combustion leading to flashback, AIAA J. 20 (1982) 254.

Lang W., PoInsot T. and CANDEl S., Active control of combustion instability, Combust. Flame 70 (1987) 281.

LANGHORNE P. J., DOWLING A. P. and Hooper N., A practical active control system for combustion oscillations. AGARD PEP Seventy-second Specialists Meeting on Combustion Instabilities in Liquid-Fueled Propulsion Systems, Bath, U.K. (1988).

LAW C. K., ZHU D. L. and YU G., Propagation and extinction of stretched premixed flames Twenty First Symposium (International) on Combustion p. 1419, The Combustion Institute (1986).

Linan A., The asymptotic structure of counterflow diffusion flames for large activation energies, Acta Astron. 1 (1974) 1007-1039.

McManus K. and Bowman C., Effects of controlling vortex dynamics on the performance of a dump combustor, Twenty-third Symposium (International) on Combustion, Orléans, France (1990).

MARble F. E. and COX D. W. Jr., Servo-stabilization of low frequency oscillations in a liquid bipropellant rocket motor, J. Am. Rock. Soc. 23 (1953) 63.

MARBLE F. E., Servo-stabilization of low frequency oscillations in liquid rocket motors, J. Appl. Math. Phys. 6 (1955) 1.

MARBLE F. E. and HENDRICKS G. J., Structure and behavior of diffusion flames in a pressure gradient. Twenty-first Symposium (International) on Combustion (The Combustion Institute, Pittsburgh, 1986) p. 1321. 
Menon S. and Jou W. H., Simulations of ramjet combustor flow fields Part. I - Numerical model, large-scale and mean motions. Nineteenth Fluid Dynamics, Plasma Dynamics, and Lasers Conference, Honolulu, Hawaii, AIAA Paper 87-1421 (1987).

MENON S. and JOU W. H., Large-eddy simulations of combustion instability in an axisymmetric ramjet combustor. Twenty-eight Aerospace Sciences Meeting, Reno, Nevada, AIAA Paper 90-0267 (1989).

Oppenheim A. V. and Shafer R. W., Digital Signal Processing (Prentice Hall, New York, 1989).

Poinsot T., Trouve A., Veynante D., Candel S. and Esposito E., Vortex driven acoustically coupled combustion instability, J. Fluid Mech. 177 (1987) 265.

Poinsot T. and CANDel S., A nonlinear model for ducted flame combustion instabilities, Combust. Sci. Tech. 61 (1988) 121.

Poinsot T, Lang W., Bourienne F., Candel S. and Esposito E., Suppression of combustion instabilities by active control, J. Propulsion Power 5 (1989a) 14.

Poinsot T., Veynante D., Bourienne F., Candel S., Esposito E. and Surget J., Initiation and suppression of combustion instabilities by active control. Twenty-second Symposium (International) on Combustion (The Combustion Institute, Pittsburgh, 1989b) p. 1363.

RAGHU S. and SREEnivasan K. R., Control of acoustically coupled combustion and fluid dynamic instabilities, Eleventh Aeroacoustics Conference, Palo Alto, California, AIAA Paper 87-2690 (1987).

Schadow K. C., Gutmark E., ParR T. P. and Wilson K. J., Control of turbulence in combustion. Turbulent Reactive Flows, US-France Joint Workshop, R. Borghi and S. N. B. Murthy, Ed. (Springer Verlag, New York, 1987) p. 912.

SCHOYER H.F. R., Incomplete combustion : a possible cause of combustion instability, AIAA J. 21 (1983) 119-1126.

Singer J. and BAU H., Active control of convection, Phys. Fluids A 3 (1991) 2859.

SREenivasan K. R., RaghU S. and ChU B. T., The control of pressure oscillations in combustion and fluid dynamical systems, AIAA Shear Flow Control Conference, Boulder, Colorado, AIAA Paper 85-0540 (1985).

SivaSEGARAM S. and WHITELAW J. H., Suppression of oscillations in confined disk-stabilized flames, $J$. Prop. 3 (1987) 291.

SPARROW C., «The Lorenz equations : bifurcations, chaos and strange attractors 》(Springer Verlag, Berlin, 1982).

STERLING J. D. and ZuKoski E. E., Longitudinal mode combustion instabilities in a dump combustor, Twenty-fifth Aerospace Sciences Meeting, Reno, Nevada, AIAA Paper 87-0220 (1987).

TSIEN H. S., Servo-stabilization of combustion in rocket motors. J. Am. Rock. Soc. 22 (1952) 256.

VANEVeld L., HOM K. and OpPENHEIM A. K., Secondary effects in combustion instabilities leading to flashback. Twentieth Aerospace Sciences Meeting, Orlando, Florida, AIAA Paper 82-0037 (1982).

VEYNANTE D. and CANDEL S., Application of nonlinear spectral analysis and signal reconstruction to laser Doppler velocimetry, Experiments in fluids 6 (1988a) 534.

VEYNANTE D. and CANDEL S. M., A promising approach in LDV data processing : signal reconstruction a nonlinear spectral analysis, Signal Processing 14 (1988b) 295.

WIDRow B., Adaptive Signal Filtering (Prentice Hall, 1985).

Williams F. A., Combustion Theory (The Benjamin/Cummings Publishing Company) 2nd Edition (1985).

YU K., Trouve A. and DaIL J J. W., Low frequency pressure oscillations in a model ramjet combustor, J. Fluid Mech. 232 (1991) 47-72.

Zrkıkout S., Mécanismes d'instabilité de combustion dans un foyer à flammes non prémélangées simulant l'injection dans un moteur fusée cryogénique, Doctoral Thesis Université Paris Sud (1988).

Zikikout S., Candel S., Poinsot T., Trouvé A. and Esposito E., High-frequency combustion oscillations produced by mode-selective excitation, Twenty-first Symposium (International) on Combustion, the Combustion Institute, Pittsburgh (1986) p. 1427. 